\title{
DWV 3C protease uncovers the diverse catalytic triad in insect RNA viruses
}

Xuye Yuan and Tatsuhiko Kadowaki

Department of Biological Sciences, Xi'an Jiaotong-Liverpool University, 111 Ren'ai Road, Suzhou Dushu Lake Higher Education Town, Jiangsu Province 215123, China

Corresponding author:

Tatsuhiko Kadowaki

Department of Biological Sciences, Xi'an Jiaotong-Liverpool University

111 Ren'ai Road, Suzhou Dushu Lake Higher Education Town

Jiangsu Province 215123, China

TEL: 8651288161659 , FAX: 8651288161899

E-mail: Tatsuhiko.Kadowaki@xjtlu.edu.cn 


\begin{abstract}
Deformed wing virus (DWV) is the most prevalent Iflavirus that is infecting honey bees worldwide. However, the mechanisms of its infection and replication in host cells are poorly understood. In this study, we analyzed the structure and function of DWV 3C protease $\left(3 \mathrm{C}^{\mathrm{pro}}\right)$, which is necessary for the cleavage of the polyprotein to synthesize mature viral proteins. We found that the $3 \mathrm{C}^{\mathrm{pro}} \mathrm{s}$ of $\mathrm{DWV}$ and picornaviruses share common enzymatic properties, including sensitivity to the same inhibitors, such as rupintrivir. The predicted structure of DWV $3 \mathrm{C}^{\text {pro }}$ by AlphaFold2, the predicted rupintrivir binding domain, and the protease activities of mutant proteins revealed that it has a Cys-His-Asn catalytic triad. Moreover, $3 \mathrm{C}^{\mathrm{pro}} \mathrm{s}$ of other Iflaviruses and Dicistrovirus appear to contain Asn, Ser, Asp, or Glu as the third residue of the catalytic triad, suggesting diversity in insect RNA viruses. Both precursor $3 C^{\text {pro }}$ with RNA-dependent RNA polymerase and mature $3 \mathrm{C}^{\text {pro }}$ are present in DWV-infected cells, suggesting that they may have different enzymatic properties and functions. DWV $3 C^{\text {pro }}$ is the first $3 \mathrm{C}^{\text {pro }}$ characterized among insect RNA viruses, and our study uncovered both the common and unique characteristics among $3 \mathrm{C}^{\mathrm{pro}} \mathrm{s}$ of Picornavirales. Furthermore, the specific inhibitors of DWV $3 C^{\text {pro }}$ could be used to control DWV infection in honey bees.
\end{abstract}

\title{
Key words
}

Deformed wing virus, $3 \mathrm{C}$ protease, Catalytic triad 


\section{Introduction}

Winter colony loss in honey bees is strongly correlated with the presence of deformed wing virus (DWV) and the ectoparasitic mites, Varroa destructor and Tropilaelaps mercedesae (Highfield et al., 2009; Nazzi and Le Conte, 2016). The mites transmit DWV to the host (de Miranda and Genersch, 2010; Rosenkranz, Aumeier and Ziegelmann, 2010; Chantawannakul et al., 2018; Wu et al., 2020) and increase viral loads (Shen et al., 2005; Wu, Dong and Kadowaki, 2017; Forsgren et al., 2009; Khongphinitbunjong et al., 2016; Wu et al., 2020). With the spread of $V$. destructor, DWV has become the most prevalent virus that is infecting honey bees worldwide (Wilfert et al., 2016). Honey bees often show multiple symptoms due to high DWV levels, including the death of pupae, deformed wings, shortened abdomen, and reduced lifespan (Yue et al., 2007; Tentcheva et al., 2004; de Miranda and Genersch, 2010; Rosenkranz, Aumeier and Ziegelmann, 2010).

DWV belongs to Iflavirus (a sister species of Dicistrovirus) in the order Picornavirales. It has a non-enveloped virion approximately $30 \mathrm{~nm}$ in diameter and contains a positive-strand RNA genome. The RNA genome is translated into a polyprotein that is processed by the $3 \mathrm{C}$ protease $\left(3 \mathrm{C}^{\mathrm{pro}}\right)$ to produce mature viral proteins (Lanzi et al., 2006). The crucial $3 \mathrm{C}^{\text {pro }}$ s have been well characterized in picornaviruses and share similar structures and functions (Matthews et al., 1994; Bergmann et al., 1997; Mosimann et al., 1997; Birtley et al., 2005; Lee et al., 2009; Ohlenschläger et al., 2004; Cui et al., 2011). Indeed, all of them have a Cys-His-Asp/Glu (Asp or Glu) catalytic triad. $3 \mathrm{C}^{\text {pro }}$ plays important roles in the viral life cycle and host-virus interactions. For example, $3 \mathrm{C}^{\text {pro }}$ not only processes a viral polyprotein but also cleaves the specific host proteins necessary for transcription, translation, and nucleocytoplasmic trafficking to modify the cell physiology for viral replication. Furthermore, $3 \mathrm{C}^{\text {pro }}$ and its precursor with RNA-dependent RNA polymerase (RdRP) bind to the 5'UTR region of the viral genome RNA to initiate replication (Yi et al., 2021; Sun et al., 2016). Based on structural conservation studies, inhibitors of picornavirus $3 \mathrm{C}^{\mathrm{pro}} \mathrm{s}$ have been identified and characterized to develop potential antiviral treatments (Lall, Jain and Vederas, 2004).

DWV is the best characterized virus among honey bee viruses; however, very little is known about its mechanism of infection and replication in host cells. In this study, we expressed and purified DWV $3 \mathrm{C}^{\text {pro }}$ as a glutathione-S-transferase (GST) fusion protein to characterize the protease activity as well as the inhibitors. We also studied the structure-function relationship of DWV $3 C^{\text {pro }}$ based on the structure predicted by AlphaFold 2 as well as the protease activities of mutant proteins compared 
to that of the $3 \mathrm{C}^{\mathrm{pro}} \mathrm{s}$ of other Iflaviruses and Dicistrovirus. We also discussed the mechanism of synthesis and maturation of DWV $3 C^{\text {pro }}$ in infected cells.

\section{Results}

\section{Enzymatic properties of DWV 3Cpro}

We expressed DWV $3 C^{\text {pro }}$ as a GST-fusion protein and further included the potential VPg region (2094-2353 of DWV polyprotein) to make it soluble in E. coli. Protease activity of DWV $3 \mathrm{C}^{\text {pro }}$ was measured by a fluorescence resonance energy transfer (FRET) assay using a 15 amino acid peptide with the potential cleavage site, AKPEMD, as the substrate. This six amino acid sequence is present at three sites in the DWV polyprotein. The optimum $\mathrm{pH}$ for protease activity was 6 (Fig. 1A), and the optimum temperature was between $25-35^{\circ} \mathrm{C}$ (Fig. 1B). Dithiothreitol was required for maximum activity as a cysteine protease (Fig. 1C) (Wilkesman, 2017). The protease activity (RFU/min) was proportional to the amount of GST-DWV 3C ${ }^{\text {pro }}$ added in the reaction mixture (Fig. 1D). Based on the Michaelis-Menten equation, Km, Vmax, and Kcat/Km values were $4.233 \pm 0.256 \mu \mathrm{M}, 0.2538 \pm 0.0067 \mu \mathrm{M} / \mathrm{min}$, and $59.96 \pm 2.032 \mathrm{mM}^{-1} \mathrm{~min}^{-1}$, respectively (Fig. 1E).

\section{Inhibitors of DWV 3Cpro}

We next tested the effects of known protease inhibitors of picornaviruses and other viruses on DWV 3C ${ }^{\text {pro }}$. Eight compounds inhibited enzyme activity with various $\mathrm{IC}_{50}$ values, as shown in Table 1. Figure 2 shows the dose-response curves for rupintrivir (Patick et al., 1999), ebselen (Amporndanai et al., 2021), disulfiram (Ma et al., 2020), GC376 (Kim et al., 2012), carmofur (Jin et al., 2020b; Ma et al., 2020), 6,7-dichloroquinoline-5,8-dione (Jung et al., 2018), quercetin (Yao et al., 2018), and zinc. Rupintrivir was the most effective compound and the $\mathrm{IC}_{50}$ value $(0.36 \mu \mathrm{M})$ was lower than that of enterovirus $3 \mathrm{C}^{\mathrm{pro}}(1.65-7.3 \mu \mathrm{M})$ but higher than that of human rhinovirus 3C ${ }^{\text {pro }}$ (5 nM) (Tan et al., 2016; Wang et al., 2011; Dragovich et al., 1999). Ebselen, disulfiram, and carmofur were only effective without dithiothreitol, as they modified cysteine in the catalytic triad (Ma et al., 2020). DWV 3C ${ }^{\text {pro }}$ is sensitive to some protease inhibitors of mammalian viruses, suggesting that their catalytic domains and substrate-binding domains share similar structures.

We previously showed that rupintrivir suppresses DWV replication in honey bee pupal cells based on the synthesis of RdRP (Wu et al., 2021). Thus, we tested the effect of ebselen on DWV replication. Ebselen decreased the synthesis of the $97 \mathrm{kDa}$ precursor of RdRP and $3 C^{\text {pro }}$ in a concentration-dependent manner (Fig. 3A and B). 
However, cell viability was reduced at concentrations of 100 and $250 \mu \mathrm{M}$ (Fig. 3C), suggesting that ebselen affects the functions of host proteins as well.

\section{Predicted structure of DWV 3C ${ }^{\text {pro }}$ by Alphafold2}

We used Alphafold2 to predict the structure of DWV 3C ${ }^{\text {pro }}$ (polyprotein 2199-2353) (Jumper et al., 2021; Mirdita et al., 2021). We obtained multiple models that are very similar to each other, and one model with the overall structure is shown in Fig. 4A. Based on the IDDT values per position, the structure was predicted with high confidence, except for the $\mathrm{N}$ - and $\mathrm{C}$-termini as well as single loop (polyprotein 2330-2332) (Supplementary figure 1). DWV 3C ${ }^{\text {pro }}$ has a trypsin-like structure consisting of six $\beta$-sheets, which are folded into two $\beta$-barrel domains packed perpendicularly to each other. The catalytic center appears to be present between the two domains. This is similar to those of other $3 \mathrm{C}^{\text {pro }} \mathrm{S}$ in addition to the position of $\beta$-ribbon (polyprotein 2281-2293) which constitutes the substrate-binding domain (Matthews et al., 1994; Bergmann et al., 1997; Mosimann et al., 1997; Birtley et al., 2005; Lee et al., 2009; Ohlenschläger et al., 2004; Cui et al., 2011) (Fig. 4A). To identify the amino acids critical for protease activity, we aligned $3 \mathrm{C}^{\text {pro }}$ sequences of DWV and 23 other Iflaviruses (Supplementary figure 2). Among the conserved 12 amino acids, the positions of C2307 and H2170 together with non-conserved N2227 in the DWV 3C ${ }^{\text {pro }}$ structure corresponded to those of the known $3 \mathrm{C}^{\text {pro }}$ catalytic triads (Matthews et al., 1994; Bergmann et al., 1997; Mosimann et al., 1997; Birtley et al., 2005; Lee et al., 2009; Ohlenschläger et al., 2004; Cui et al., 2011). Although Y2171 was well conserved, its position relative to $\mathrm{H} 2170$ did not appear to be compatible with the third residue of the catalytic triad. There is also D2225, but the side chain with a carboxyl group was oriented in the opposite direction (Fig. 4C and D). The predicted distances between $\mathrm{C} 2307$ and $\mathrm{H} 2170$ as well as $\mathrm{H} 2170$ and N2227 were $4.03 \AA$ and $3.22 \AA$, respectively in range of interaction (Fig. 4B). We also predicted the $3 \mathrm{C}^{\text {pro }}$ structures of four different Iflaviruses: Brevicoryne brassicae virus (BrBV), Laodelphax striatellus picorna-like virus 2 (LsPVI2), Sacbrood virus (SBV), and Spodoptera exigua iflavirus (SeIV-1), and one Dicistrovirus, Cricket paralysis virus (CrPV). For the catalytic triads, all of them had Cys and His residues; however, BrBV, LsPVI2, and SeIV-1 appeared to contain Asn, Ser, and Glu, respectively, as the third residue. SBV and CrPV appeared to have Asp (Supplementary figure 3). Thus, $3 C^{\text {pro }}$ of insect RNA virus is likely to have invariant Cys as well as His and various amino acid with side chain containing oxygen as the catalytic triad.

To prove that the structure of DWV $3 C^{\text {pro }}$ predicted by Alphafold2 is correct, we prepared mutant proteins in which the potentially critical amino acid was substituted 
with alanine and measured the protease activities. The activities were dramatically reduced with the mutant proteins for the catalytic triad (C2307, H2170, and N2227) and substrate binding domains, including conserved Y2299 and H2324 domains (Fig. 4C and F). N2134 of DWV is also well conserved between the $3 \mathrm{C}^{\text {pro }} \mathrm{s}$ of Iflaviruses, but it localizes far from the catalytic center (Fig. 4D). Nevertheless, we found that the protease activity of the N2134A mutant was reduced to approximately one-third of that of the wild type protein (Fig. 4F). A previous study suggested that H2190 and D2225 constitute the catalytic triad together with C2307 (Lanzi et al., 2006). However, H2190 was far from C2307 (Fig. 4E), and the H2190A mutant and wild type protein showed comparable protease activity (Fig. 4F). D2225 is close to N2227 as described above, but the protease activity of $\mathrm{D} 2225 \mathrm{~A}$ was reduced to only half of that of the wild type protein (Fig. 4F). Thus, H2190 and D2225 are not part of the catalytic triad of DWV 3C ${ }^{\text {pro }}$. D2304A and E2329A mutants have the same activity as the wild type protein, indicating that they are not the third residue of the catalytic triad (Fig. 4E and F). The above results demonstrate that the Alphafold2 predicted structure of DWV $3 C^{\text {pro }}$ should be correct.

We next determined how rupintrivir binds DWV $3 C^{\text {pro }}$ to inhibit its activity using a molecular docking tool. Rupintrivir was predicted to interact with 16 amino acids in the catalytic triad (C2307, H2170, and N2227) as well as a substrate-binding domain. Nitrogen atoms in the side chains of N2227 and H2324 appeared to form hydrogen bonds with rupintrivir. Five amino acids (I2283, N2284, A2285, L2288, and Y2289) in $\beta$-ribbon also appeared to interact with rupintrivir (Fig. 5A, B, and E). Thus, $3 \mathrm{C}^{\mathrm{pro}} \mathrm{s}$ of DWV and picornaviruses appear to bind rupintrivir in a similar manner (Wang et al., 2011; Matthews et al., 1994; Binford et al., 2005). Analysis of rupintrivir binding with DWV $3 \mathrm{C}^{\text {pro }}$ revealed a precise map of the amino acids critical for protease activity at the protein surface. The catalytic triad (C2307, H2170, and N2227) are adjacent to each other; R2156 and Y2171 are adjacent to C2307 and H2170. The largely reduced protease activities of $\mathrm{R} 2156 \mathrm{~A}$ and $\mathrm{Y} 2171 \mathrm{~A}$ mutants were consistent with their localization (Fig. 4F). The substrate-binding domain is composed of two grooves on the left and right sides, and V2325 and A2326 are in the middle to connect them. The left groove was constructed using H2302, G2303, D2304, G2305, H2324, G2327, and E2329. Among them, H2302, G2303, D2304, and E2329 create a porous structure. The deep right groove is made by R2169, E2173, I2283, N2284, A2285, L2288, Y2289, and V2291. Most of the amino acids were in the $\beta$-ribbon structure (Fig. $5 \mathrm{C}$ and D).

\section{Self-cleavage of GST-DWV 3Cpro}


When we purified the $56 \mathrm{kDa}$ wild-type GST-DWV $3 \mathrm{C}^{\text {pro }}$ protein, a $30 \mathrm{kDa}$ small band was co-purified. This band was absent in the mutant protein lacking protease activity, for example, C2307A (Fig. 6A). These results suggest that the $30 \mathrm{kDa}$ band was generated by the self-cleavage of GST-DWV $3 C^{\text {pro }}$ either by cis or trans. Our DWV $3 C^{\text {pro }}$ fusion protein contains two potential cleavage sites, Q2118 and E2180 (Lanzi et $a l .$, 2006). To determine the cleavage site, we prepared mutant proteins in which one of the above two amino acids was substituted with alanine. As shown in Figure 6A, the 30 $\mathrm{kDa}$ band was absent only in the Q2118A mutant, suggesting that GST-DWV 3C ${ }^{\text {pro }}$ is self-cleaved at Q2118 in E. coli. We also tested whether the purified GST-DWV 3C was self-cleaved during incubation at $33{ }^{\circ} \mathrm{C}$ and found that it remained stable without self-cleavage for $18 \mathrm{~h}$ (Fig. 6B).

\section{Synthesis of 3C ${ }^{\text {pro }}$ in DWV-infected honey bee cells}

To characterize the $3 C^{\text {pro }}$ synthesized in DWV-infected honey bee cells, we raised antibodies against DWV 3C ${ }^{\text {pro }}$. We found that a $97 \mathrm{kDa}$ protein specifically present in DWV-infected cells is recognized by both anti-3C pro and anti-RdRP antibodies, confirming that this is a $3 C^{\text {pro }}$ precursor with RdRP. There was also a $42 \mathrm{kDa}$ band specifically recognized by the anti-3C $\mathrm{C}^{\text {pro }}$ antibody, suggesting that this corresponds to the mature $3 \mathrm{C}^{\text {pro }}$ in DWV-infected cells (Fig. 6C). Thus, DWV 3C ${ }^{\text {pro }}$ is present as both a precursor and a mature protein in the infected cells.

\section{Discussion}

Compared to the $\mathrm{Km}$ values of the best peptide substrate for $3 \mathrm{C}^{\mathrm{pro}} \mathrm{s}$ of human rhinovirus $(250 \mu \mathrm{M})$, poliovirus $(7 \mu \mathrm{M})$, and enterovirus (30 and $43 \mu \mathrm{M})$ (Cordingley et al., 1989; Weidner and Dunn, 1991; Shang et al., 2015; Cui et al., 2011), DWV 3C ${ }^{\text {pro }}$ has a higher affinity for the peptide substrate used in this study $(\mathrm{Km}: 4.233 \mu \mathrm{M})$. Nevertheless, DWV polyprotein has other potential cleavage sites by $3 \mathrm{C}^{\text {pro }}$ so that the efficiency of cleaving a peptide substrate containing these sites would be varied. The $\mathrm{Kcat} / \mathrm{Km}$ value of DWV 3C ${ }^{\text {pro }}$ was $59.96 \mathrm{mM}^{-1} \mathrm{~min}^{-1}$ and comparable to those of hepatitis A virus (126 $\left.\mathrm{mM}^{-1} \mathrm{~min}^{-1}\right)$, enterovirus (11.8 and $\left.0.71 \mathrm{mM}^{-1} \mathrm{~min}^{-1}\right)$, and foot-and-mouth disease virus (59.4 $\mathrm{mM}^{-1} \mathrm{~min}^{-1}$ ) $3 \mathrm{C}^{\mathrm{pro}} \mathrm{s}$ with their best substrates (Jewell et al., 1992; Shang et al., 2015; Cui et al., 2011; Sweeney et al., 2007). These results suggest that the presence of Asn instead of Asp/Glu in the catalytic triad of DWV 3C ${ }^{\text {pro }}$ does not dramatically affect protease activity. In fact, substituting Asp in the catalytic triad of hepatitis A virus $3 C^{\text {pro }}$ with Asn only resulted in slower processing (Gosert, Dollenmaier and Weitz, 1997).

Ebselen, disulfiram, and carmofur have been shown to inhibit the main protease of SARS-CoV-2 by covalently modifying cysteine in the catalytic diad (Jin et 
al., 2020b; Ma et al., 2020; Amporndanai et al., 2021). Although we were not able to predict the binding site of ebselen in DWV $3 \mathrm{C}^{\text {pro }}$ using a molecular docking approach, it is likely to target $\mathrm{C} 2307$ in the catalytic triad to inhibit protease activity. Ebselen inhibited DWV replication in honey bee cells; however, it was also toxic to the cells (Fig. 3). Thus, ebselen (MW: 274.18) could be a potential lead compound for fragment-based drug discovery approaches to increase the specificity and potency to DWV $3 C^{\text {pro }}$. Whether the $3 \mathrm{C}^{\text {pro }}$ inhibitors we identified could be effective in controlling DWV in honey bees remains to be tested.

In contrast to picornaviruses, DWV 3C $\mathrm{C}^{\text {pro }}$ contains Asn (N2227) as the third residue of the catalytic triad instead of Asp/Glu (Fig. 4A and B). Moreover, Asn is not conserved among Iflaviruses, and in fact other Iflaviruses and Dicistrovirus appear to have Asn/Ser/Glu/Asp residue (Supplementary Figs. 2 and 3). The third residue of the triad could be flexible as long as it contained an oxygen in the side chain. Oxygen is necessary to maintain the entire architecture of the active site and stabilize the positively charged imidazole side chain of His during proteolysis (Wang et al., 2011). Meanwhile, Cys and His in the catalytic triad are under strong negative selection, suggesting that they are the most critical amino acids for protease reaction. This is consistent with the fact that the main protease of coronavirus has the Cys-His catalytic diad (Jin et al., 2020a). Because the N2227A mutant completely lost its protease activity (Fig. 4F), and the same was observed with other $3 \mathrm{C}^{\mathrm{pro}} \mathrm{s}$ (Cheah, Leong and Porter, 1990; Hämmerle, Hellen and Wimmer, 1991; Miyashita et al., 1993), the catalytic triad seems to be necessary for Picornavirales. In many Iflaviruses, the Tyr residue next to the His residue of the catalytic triad (Y2171 for DWV) is conserved and is substituted with Phe in the Dicistrovirus, CrPV. Thus, Tyr appears to be important to position the imidazole side chain of His close to the side chain of Cys by stacking interactions.

The pores made by H2302, G2303, D2304, and E2329 in the left groove of the substrate-binding domain did not appear to be essential because the protease activities of the D2304A and E2329A mutants were not affected (Fig. 4F). $\beta$-ribbon is the major component of the deep right groove of the substrate-binding domain. In picornavirus $3 \mathrm{C}^{\mathrm{pro}} \mathrm{s}$, the $\beta$-ribbon adopts an open conformation to increase the substrate accessibility to its binding domain, and the interaction between the $\beta$-ribbon and the $\mathrm{N}$-terminal end of the substrate stabilizes the closed conformation to form an ES complex (Matthews et al., 1994; Bergmann et al., 1997; Mosimann et al., 1997; Birtley et al., 2005; Lee et al., 2009; Ohlenschläger et al., 2004; Cui et al., 2011). Comparing the surface views of the substrate-binding domains of DWV, BrBV, LsPVI2, SeIV-1, SBV, and CrPV 3C ${ }^{\text {pro }}$ (Fig. $5 \mathrm{C}$ and D; Supplementary figure 4), the overall conformation of the catalytic triad and 
$\beta$-ribbon was similar, but the shapes of substrate binding domains were quite different. Thus, the structure of the substrate-binding domain of each $3 \mathrm{C}^{\text {pro }}$ is shaped by a preferred cleavage site with a different amino acid sequence.

We found that GST-DWV 3C ${ }^{\text {pro }}$ was self-cleaved at Q2118. However, this seems to only occur during the synthesis in E. coli because the mature folded protein was not self-cleaved at $33{ }^{\circ} \mathrm{C}$ for $18 \mathrm{~h}$ (Fig. 6B). These results suggest that only the fraction of unfolded GST-DWV $3 \mathrm{C}^{\text {pro }}$ is cleaved in trans at $15^{\circ} \mathrm{C}$. It is likely that DWV polyprotein is cleaved at Q2118 to release the $97 \mathrm{kDa}$ precursor of $3 \mathrm{C}^{\text {pro }}$ and RdRP. However, we need to assume that the $97 \mathrm{kDa}$ precursor is active as a protease similar to picornavirus 3CD precursor (Winston and Boehr, 2021) and that cleavage should occur in $c i s$, at least during the early stage of polyprotein synthesis until a sufficient $97 \mathrm{kDa}$ precursor and $42 \mathrm{kDa}$ mature $3 \mathrm{C}^{\text {pro }}$ s accumulate in DWV-infected cells. Because the 97 $\mathrm{kDa}$ precursor remains abundant in the virus-infected honey bee cells (Fig. 6C), processing between $3 C^{\text {pro }}$ and RdRP appears to be slower than the cleavage at Q2118. These characteristics appear to be shared among picornaviruses as well (Jiang et al., 2014). It will be interesting to test whether the $97 \mathrm{kDa}$ precursor and $42 \mathrm{kDa}$ mature $3 C^{\text {pro }}$ s have different protease activities and functions for viral RNA replication in future studies.

\section{Materials and Methods}

\section{Expression and purification of GST-DWV 3Cpro}

The 3C protease cDNA corresponding to amino acid 2094-2353 of DWV polyprotein was amplified by PCR using two primers, GST-3C ${ }^{\text {pro }}-5$-BamHI and GST-3C ${ }^{\text {pro }}-3$-NotI (Supplementary Table 1). The amplified PCR product was digested by BamHI (NEB) and NotI (NEB), and then subcloned to pGEX-4T-1vector (Cytiva) followed by transformation to BL21. The transformed BL21 was grown in $1 \mathrm{~L}$ of LB medium containing $1 \%$ glucose and $0.1 \mathrm{mg} / \mathrm{mL}$ Ampillicin at $37{ }^{\circ} \mathrm{C}$ until $\mathrm{A}_{600}$ reached to 0.5 . The cell suspension was cooled down, and then IPTG was added at $0.1 \mathrm{mM}$ to induce the protein expression at $15{ }^{\circ} \mathrm{C}$ for $16 \mathrm{~h}$. E. coli was collected by centrifugation and resuspended in $100 \mathrm{~mL}$ of ice-cold TNED buffer $(50 \mathrm{mM}$ Tris- $\mathrm{HCl}, \mathrm{pH} 8.0,150 \mathrm{mM}$ NaCl, 2 mM EDTA, 1 mM DTT) with $0.5 \%$ TX-100 and protease inhibitor cocktail (Beyotime). The cell lysate was prepared by sonication using Q700 Sonicator (Qsonica) at amplitude 100 on ice for $45 \mathrm{~min}$ (30 sec pulse with 3 min-interval). $1 \mathrm{~mL}$ of BeyoGold ${ }^{\text {TM }}$ GST-tag Purification Resin (Beyotime) was added to the supernatant collected after centrifugation. After gently rotating at $4{ }^{\circ} \mathrm{C}$ for $2 \mathrm{~h}$, the resin was washed five times with $10 \mathrm{~mL}$ TNED buffer. The bound protein was eluted with $1.5 \mathrm{~mL}$ TNED 
buffer containing $10 \mathrm{mM}$ reduced glutathione. The two-thirds of eluted protein was dialyzed against $2 \mathrm{~L}$ of TNED buffer twice at $4{ }^{\circ} \mathrm{C}$ for $24 \mathrm{~h}$. The rest of one-third was dialyzed against $2 \mathrm{~L}$ of TNE buffer without DTT. We measured the protein concentation of purified protein using Enhanced BCA Protein Assay Kit (Beyotime).

GST-3C ${ }^{\text {pro }}$ mutant proteins were generated by fusion PCR of two PCR products amplified using pGEX 5' primer as well as the reverse primer for each mutant and pGEX 3' primer as well as the forward primer for each mutant (Supplementary Table 1). The plasmid DNA to express GST-DWV 3C ${ }^{\text {pro }}$ was used as the template for the 1st PCR. The fusion PCR products were cloned in pGEX-4T-1vector and the mutant proteins were expressed and purified as above. All plasmid DNAs were sequenced to verify the intended mutations.

\section{Protease assay of GST-DWV 3Cpro}

Dabcyl-PVQAKPEMDNPNPGE-Edans derived from the cleavage site between L-protein and VP2 (underlined, 205-218 of polyprotein) was used as a peptide substrate to measure the protease activity. $\mathrm{E}$ was added to the $\mathrm{C}$-terminus to link Edans. FRET experiments were performed with Varioskan ${ }^{\mathrm{TM}}$ LUX multimode microplate reader (Thermo Fisher). We measured $100 \mu \mathrm{L}$ of reaction mixture with $50 \mathrm{mM}$ Citrate buffer, pH 6.0, $150 \mathrm{mM} \mathrm{NaCl}, 2 \mathrm{mM}$ EDTA, $2 \mathrm{mM}$ DTT containing $1 \mu \mathrm{M}$ GST-DWV 3C $\mathrm{Cro}^{\text {pro }}$ and $20 \mu \mathrm{M}$ fluorogenic peptide substrate in a 96-well flat-bottom white microplate at $33{ }^{\circ} \mathrm{C}$. The relative fluorescence was measured using an excitation wavelength of 336 $\mathrm{nm}$ and by monitoring the emission at $490 \mathrm{~nm}$ every $3 \mathrm{~min}$ for $30 \mathrm{~min}$. In order to determine the optimal reaction condition for GST-DWV $3 \mathrm{C}^{\mathrm{pro}}$, various $\mathrm{pH}$ values, temperatures, and DTT concentrations were used. To test the effect of DTT on the activity, the protein dialyzed against TNE buffer was used. To determine the velocity of product formation, we precalibrated the instrument with the free Edans standard in the presence of $20 \mu \mathrm{M}$ Dabcyl to calculate the relationship between relative fluorescence and substrate concentration. We calculated the kinetic parameters, Km, Vmax, and catalytic efficiency $(\mathrm{Kcat} / \mathrm{Km})$ assuming Michaelis-Menten kinetics for the cleavage of peptide. No significant hydrolysis of the peptide substrates was observed in the absence of GST-DWV 3C ${ }^{\text {pro }}$.

To identify the inhibitors for DWV $3 C^{\text {pro }}$, various concentrations of the tested compounds were added. To determine the inhibitory effects of the various compounds, we preincubated the compound and enzyme on ice for 10 min prior to addition of the peptide substrate. To analyze the effects of ebselen, disulfiram, and carmofur, we used the enzyme dialyzed against TNE buffer and carried out the reaction with or without DTT. We determined the initial velocities of the enzymatic reactions and fitted to a 
sigmoidal dose-response equation with nonlinear regression analysis using GraphPad Prism 9. The data from three independent assays were used to determine IC50 value of each compound.

\section{Infection of honey bee pupal head cells with DWV}

Honey bee pupae with pale/pink eyes were collected from a mite-free colony. They were surface sterilized by washing with $10 \%$ bleach followed by sterile PBS three times ( 5 min for each wash). Heads from the pupae were dissected and homogenized seven times with $1 \mathrm{~mL}$ Grace culture medium using Dounce homogenizer (Loose fitting). The homogenate was then filtered through a cell strainer (Falcon) and the number of cells was counted. $10^{6}$ cells were suspended in $100 \mu \mathrm{L}$ of Grace medium containing $10 \%$ FBS, antibiotics (penicillin and streptomycin), and ebselen at the indicated concentration with or without DWV (MOI: 10) in 24 -well plate at $33{ }^{\circ} \mathrm{C}$ for 1 h. Fresh culture medium $(400 \mu \mathrm{L})$ with ebselen at the indicated concentration was then added (the final cell density at $2 \times 10^{6} / \mathrm{mL}$ ) and incubated at $33{ }^{\circ} \mathrm{C}$ for $16 \mathrm{~h}$.

\section{Western blot}

After DWV infection, the pupal head cells were collected by centrifugation, and then homogenized with $150 \mu \mathrm{L}$ of RIPA buffer (20 mM Tris-HCl, $\mathrm{pH} 7.5,150 \mathrm{mM} \mathrm{NaCl}$, $1 \%$ NP-40, $0.5 \%$ sodium deoxycholate, $0.1 \%$ SDS) containing protease inhibitor cocktail. After centrifugation of the homogenate, the protein concentration of supernatant was measured using Enhanced BCA protein assay kit. The cell lysate with $20 \mu \mathrm{g}$ of protein was analyzed by western blot for each sample. The protein samples in SDS-PAGE sample buffer ( $2 \%$ SDS, $10 \%$ glycerol, $10 \% \beta$-mercaptoethanol, $0.25 \%$ bromophenol blue, $50 \mathrm{mM}$ Tris-HCl, $\mathrm{pH} 6.8$ ) were heated at $95{ }^{\circ} \mathrm{C}$ for $5 \mathrm{~min}$. After centrifugation, the supernatants were applied to $10 \%$ SDS-PAGE and the proteins were transferred to a nitrocellulose membrane (Pall ${ }^{\circledR}$ Life Sciences). Another $10 \%$ SDS-PAGE gel with the same samples was stained by Instant Blue. The membrane was then blocked with PBST (PBS with $0.1 \%$ Tween-20) containing $5 \%$ BSA at room temperature for $30 \mathrm{~min}$ followed by incubating with 1000-fold diluted anti-RdRP antibody (Wu et al., 2020) or 500-fold diluted anti-3C $\mathrm{C}^{\text {pro }}$ antibody at $4{ }^{\circ} \mathrm{C}$ overnight. The membrane was washed five times with PBST (5 min each), and then incubated with 10,000-fold diluted IRDye ${ }^{\circledR}$ 680RD donkey anti-rabbit IgG (H+L) (LI-COR Biosciences) in PBST containing $5 \%$ skim milk at room temperature for $2 \mathrm{~h}$. The membrane was washed as above, and then visualized using Odyssey Imaging System (LI-COR Biosciences). Band intensity of $97 \mathrm{kDa}$ RdRP precursor was measured by image-J.

\section{Testing cell viability}


Honey bee pupal head cells were prepared as above and $100 \mu \mathrm{L}$ cell suspension $(2 \times$ $10^{6} / \mathrm{mL}$ ) was inoculated to each well in 96-well plate. The cells were cultured in the presence of either DMSO or ebselen at the indicated concentrations at $33{ }^{\circ} \mathrm{C}$ for $16 \mathrm{~h}$. The cultured plate was first incubated at room temperature for $10 \mathrm{~min}$ followed by adding $100 \mu \mathrm{L}$ of reagent solution (CellTiter-Lumi ${ }^{\text {TM }}$ Luminescent Cell Viability Assay Kit, Beyotime). The plate was shaken at room temperature for $2 \mathrm{~min}$ to promote cell lysis, and then further incubated for $10 \mathrm{~min}$ to stabilize the chemiluminescence signal. The signal was detected using Varioskan ${ }^{\mathrm{TM}}$ LUX multimode microplate reader and depends on intracellular ATP level, thus the relative viability of cells.

\section{Structural analysis of 3C proteases of DWV and other insect RNA viruses}

We determined the structures of 3C proteases of DWV, BrBV, LsPVI2, SeIV-1, SBV, and CrPV using ColabFold (Mirdita et al., 2021) based on AlphaFold v2.1.0 (Jumper et al., 2021). The generated structures were analyzed and displayed using UCSF ChimeraX (Pettersen et al., 2021; Goddard et al., 2018). The molecular structure of rupintrivir was collected from PubChem (CID: 6440352). We used AutoDock Tools package (Morris et al., 2009) to prepare the ligand and receptor by removing water and other heteroatoms and assigning partial charges. The size of the grid box for docking was set at $20 \AA$ in each direction. We provided explicit coordinate to find all possible binding sites. After preparing the ligand, receptor, definition of binding site, AutoDock Vina (version 1.1.2) (Trott and Olson, 2010) program was used for the molecular docking simulation.

\section{Self-cleavage of GST-DWV 3Cpro}

$10 \mu \mathrm{g}$ of wild type, C2307A, Q2118A, and E2180A GST-DWV 3C ${ }^{\text {pro }}$ protein was analyzed by $10 \%$ SDS-PAGE followed by Instant Blue staining. $20 \mu \mathrm{g}$ of wild type GST-DWV $3 C^{\text {pro }}$ was incubated in the enzyme reaction buffer without the substrate at $33{ }^{\circ} \mathrm{C}$ and the $4 \mu \mathrm{g}$ protein was sampled every $3 \mathrm{~h}$ for $12 \mathrm{~h}$ and at $18 \mathrm{~h}$. All samples including the one without the incubation $(0 \mathrm{~h})$ were analyzed by SDS-PAGE as above.

\section{Preparation of anti-DWV $3 C^{\text {pro }}$ antibody}

DWV $3 C^{\text {pro }}$ insert in pGEX-4T-1 was transferred to pGEX-6P-3 followed by transformation to BL21. The protein was expressed and purified as above except $5 \mathrm{~mL}$ TNED buffer containing 100 units of PreScission Protease (Beyotime) was added to the resin after the final wash. The resin was incubated at $4{ }^{\circ} \mathrm{C}$ overnight and the supernatant with the released DWV $3 C^{\text {pro }}$ was collected. The remaining resin was eluted once with 5 $\mathrm{mL}$ TNED buffer and the eluate was combined with the above supernatant. The total eluate was dialyzed against 2L of PBS with $1 \mathrm{mM}$ EDTA, $0.5 \mathrm{mM} \mathrm{DTT}$, and $0.1 \%$ 
sarcosyl twice at $4{ }^{\circ} \mathrm{C}$ for $24 \mathrm{~h}$. The purified protein was delivered to GeneScript-Nanjing to raise the anti-rabbit polyclonal antibody.

\section{Alignment of Ifravirus $3 \mathrm{C}$ protease sequences}

$3 \mathrm{C}$ protease sequences of various Iflaviruses were searched in NCBI by BLASTP using DWV $3 C^{\text {pro }}$ sequence as a query. Twenty three sequences were picked up and aligned together with DWV $3 C^{\text {pro }}$ using MUSCLE program (EMBL-EBI).

\section{Statistical analysis}

All data presented were from representative independent experiments. Statistical analyses were performed with Bell Curve for Excel (Social Survey Research Information Co., Ltd.) and no data point was excluded. The applied statistical tests and $P$-values are described in figure legends.

\section{Conflict of interest statement}

The authors declare no conflict of interest.

\section{Author contribution}

TK conceived and designed research strategy and wrote the paper. XY performed the experiments. XY and TK analyzed data.

\section{Funding}

This work was supported by Jinji Lake Double Hundred Talents Programme and XJTLU Summer Undergraduate Research Fellowship (SURF 2021095) to TK.

\section{Acknowledgements}

We thank Yixiang Tang, Shiqi Xu, Jiarui Li, Zhuoran Leng, and Shangqing Li for their contributions to conduct the experiments. We are grateful to Dr. David Ruiz-Carrillo for his comments on the paper.

\section{References}

Amporndanai, K., Meng, X., Shang, W., Jin, Z., Rogers, M., Zhao, Y., Rao, Z., Liu, Z. J., Yang, H., Zhang, L., O'Neill, P. M. and Samar Hasnain, S. (2021) 'Inhibition mechanism of SARS-CoV-2 main protease by ebselen and its derivatives', Nat Commun, 12(1), pp. 3061.

Bergmann, E. M., Mosimann, S. C., Chernaia, M. M., Malcolm, B. A. and James, M. N. (1997) 'The refined crystal structure of the 3C gene product from hepatitis A virus: specific proteinase activity and RNA recognition', J Virol, 71(3), pp. 2436-48. 
Binford, S. L., Maldonado, F., Brothers, M. A., Weady, P. T., Zalman, L. S., Meador, J. W., Matthews, D. A. and Patick, A. K. (2005) 'Conservation of amino acids in human rhinovirus $3 \mathrm{C}$ protease correlates with broad-spectrum antiviral activity of rupintrivir, a novel human rhinovirus 3C protease inhibitor', Antimicrob Agents Chemother, 49(2), pp. 619-26.

Birtley, J. R., Knox, S. R., Jaulent, A. M., Brick, P., Leatherbarrow, R. J. and Curry, S. (2005) 'Crystal structure of foot-and-mouth disease virus 3C protease. New insights into catalytic mechanism and cleavage specificity', J Biol Chem, 280(12), pp. 11520-7.

Chantawannakul, P., Ramsey, S., vanEngelsdorp, D., Khongphinitbunjong, K. and Phokasem, P. (2018) 'Tropilaelaps mite: an emerging threat to European honey bee', Curr Opin Insect Sci, 26, pp. 69-75.

Cheah, K. C., Leong, L. E. and Porter, A. G. (1990) 'Site-directed mutagenesis suggests close functional relationship between a human rhinovirus $3 \mathrm{C}$ cysteine protease and cellular trypsin-like serine proteases', J Biol Chem, 265(13), pp. 7180-7.

Cordingley, M. G., Register, R. B., Callahan, P. L., Garsky, V. M. and Colonno, R. J. (1989) 'Cleavage of small peptides in vitro by human rhinovirus 14 3C protease expressed in Escherichia coli', J Virol, 63(12), pp. 5037-45.

Cui, S., Wang, J., Fan, T., Qin, B., Guo, L., Lei, X., Wang, M. and Jin, Q. (2011) 'Crystal structure of human enterovirus 71 3C protease', J Mol Biol, 408(3), pp. 449-61. de Miranda, J. R. and Genersch, E. (2010) 'Deformed wing virus', J Invertebr Pathol, 103 Suppl 1, pp. S48-61.

Dragovich, P. S., Prins, T. J., Zhou, R., Webber, S. E., Marakovits, J. T., Fuhrman, S. A., Patick, A. K., Matthews, D. A., Lee, C. A., Ford, C. E., Burke, B. J., Rejto, P. A., Hendrickson, T. F., Tuntland, T., Brown, E. L., Meador, J. W., Ferre, R. A., Harr, J. E., Kosa, M. B. and Worland, S. T. (1999) 'Structure-based design, synthesis, and biological evaluation of irreversible human rhinovirus 3C protease inhibitors. 4. Incorporation of P1 lactam moieties as L-glutamine replacements', J Med Chem, 42(7), pp. 1213-24.

Forsgren, E., de Miranda, J. R., Isaksson, M., Wei, S. and Fries, I. (2009) 'Deformed wing virus associated with Tropilaelaps mercedesae infesting European honey bees (Apis mellifera)', Exp Appl Acarol, 47(2), pp. 87-97.

Goddard, T. D., Huang, C. C., Meng, E. C., Pettersen, E. F., Couch, G. S., Morris, J. H. and Ferrin, T. E. (2018) 'UCSF ChimeraX: Meeting modern challenges in visualization and analysis', Protein Sci, 27(1), pp. 14-25. 
Gosert, R., Dollenmaier, G. and Weitz, M. (1997) 'Identification of active-site residues in protease $3 \mathrm{C}$ of hepatitis A virus by site-directed mutagenesis', J Virol, 71(4), pp. 3062-8.

Highfield, A. C., El Nagar, A., Mackinder, L. C., Noël, L. M., Hall, M. J., Martin, S. J. and Schroeder, D. C. (2009) 'Deformed wing virus implicated in overwintering honeybee colony losses', Appl Environ Microbiol, 75(22), pp. 7212-20.

Hämmerle, T., Hellen, C. U. and Wimmer, E. (1991) 'Site-directed mutagenesis of the putative catalytic triad of poliovirus 3C proteinase', J Biol Chem, 266(9), pp. 5412-6.

Jewell, D. A., Swietnicki, W., Dunn, B. M. and Malcolm, B. A. (1992) 'Hepatitis A virus 3C proteinase substrate specificity', Biochemistry, 31(34), pp. 7862-9.

Jiang, P., Liu, Y., Ma, H. C., Paul, A. V. and Wimmer, E. (2014) 'Picornavirus morphogenesis', Microbiol Mol Biol Rev, 78(3), pp. 418-37.

Jin, Z., Du, X., Xu, Y., Deng, Y., Liu, M., Zhao, Y., Zhang, B., Li, X., Zhang, L., Peng, C., Duan, Y., Yu, J., Wang, L., Yang, K., Liu, F., Jiang, R., Yang, X., You, T., Liu, X., Bai, F., Liu, H., Guddat, L. W., Xu, W., Xiao, G., Qin, C., Shi, Z., Jiang, H., Rao, Z. and Yang, H. (2020a) 'Structure of M', Nature, 582(7811), pp. 289-293.

Jin, Z., Zhao, Y., Sun, Y., Zhang, B., Wang, H., Wu, Y., Zhu, Y., Zhu, C., Hu, T., Du, X., Duan, Y., Yu, J., Yang, X., Yang, K., Liu, X., Guddat, L. W., Xiao, G., Zhang, L., Yang, H. and Rao, Z. (2020b) 'Structural basis for the inhibition of SARS-CoV-2 main protease by antineoplastic drug carmofur', Nat Struct Mol Biol, 27(6), pp. 529-532.

Jumper, J., Evans, R., Pritzel, A., Green, T., Figurnov, M., Ronneberger, O., Tunyasuvunakool, K., Bates, R., Žídek, A., Potapenko, A., Bridgland, A., Meyer, C., Kohl, S. A. A., Ballard, A. J., Cowie, A., Romera-Paredes, B., Nikolov, S., Jain, R., Adler, J., Back, T., Petersen, S., Reiman, D., Clancy, E., Zielinski, M., Steinegger, M., Pacholska, M., Berghammer, T., Bodenstein, S., Silver, D., Vinyals, O., Senior, A. W., Kavukcuoglu, K., Kohli, P. and Hassabis, D. (2021) 'Highly accurate protein structure prediction with AlphaFold', Nature, 596(7873), pp. 583-589.

Jung, E., Lee, J. Y., Kim, H. J., Ryu, C. K., Lee, K. I., Kim, M., Lee, C. K. and Go, Y. Y. (2018) 'Identification of quinone analogues as potential inhibitors of picornavirus 3C protease in vitro', Bioorg Med Chem Lett, 28(14), pp. 2533-2538.

Khongphinitbunjong, K., Neumann, P., Chantawannakul, P. and Williams, G. (2016) 'The ectoparasitic mite Tropilaelaps mercedesae reduces western honey bee, Apis mellifera, longevity and emergence weight, and promotes Deformed wing virus infections', Journal of Invertebrate Pathology, 137, pp. 38-42.

Kim, Y., Lovell, S., Tiew, K. C., Mandadapu, S. R., Alliston, K. R., Battaile, K. P., Groutas, W. C. and Chang, K. O. (2012) 'Broad-spectrum antivirals against 3C or 
3C-like proteases of picornaviruses, noroviruses, and coronaviruses', J Virol, 86(21), pp. 11754-62.

Lall, M. S., Jain, R. P. and Vederas, J. C. (2004) 'Inhibitors of 3C cysteine proteinases from Picornaviridae', Curr Top Med Chem, 4(12), pp. 1239-53.

Lanzi, G., de Miranda, J. R., Boniotti, M. B., Cameron, C. E., Lavazza, A., Capucci, L., Camazine, S. M. and Rossi, C. (2006) 'Molecular and biological characterization of deformed wing virus of honeybees (Apis mellifera L.)', J Virol, 80(10), pp. 4998-5009.

Lee, C. C., Kuo, C. J., Ko, T. P., Hsu, M. F., Tsui, Y. C., Chang, S. C., Yang, S., Chen, S. J., Chen, H. C., Hsu, M. C., Shih, S. R., Liang, P. H. and Wang, A. H. (2009) 'Structural basis of inhibition specificities of $3 \mathrm{C}$ and 3C-like proteases by zinc-coordinating and peptidomimetic compounds', J Biol Chem, 284(12), pp. 7646-55.

Ma, C., Hu, Y., Townsend, J. A., Lagarias, P. I., Marty, M. T., Kolocouris, A. and Wang, J. (2020) 'Ebselen, Disulfiram, Carmofur, PX-12, Tideglusib, and Shikonin Are Nonspecific Promiscuous SARS-CoV-2 Main Protease Inhibitors', ACS Pharmacol Transl Sci, 3(6), pp. 1265-1277.

Matthews, D. A., Smith, W. W., Ferre, R. A., Condon, B., Budahazi, G., Sisson, W., Villafranca, J. E., Janson, C. A., McElroy, H. E. and Gribskov, C. L. (1994) 'Structure of human rhinovirus 3C protease reveals a trypsin-like polypeptide fold, RNA-binding site, and means for cleaving precursor polyprotein', Cell, 77(5), pp. 761-71.

Mirdita, M., Schütze, K., Moriwaki, Y., Heo, L., Ovchinnikov, S. and Steinegger, M. 2021. ColabFold - Making protein folding accessible to all. bioRxiv https://doi.org/10.1101/2021.08.15.456425.

Miyashita, K., Kusumi, M., Utsumi, R., Katayama, S., Noda, M., Komano, T. and Satoh, N. (1993) 'Site-directed mutagenesis of the putative active site residues of 3C proteinase of coxsackievirus B3: evidence of a functional relationship with trypsin-like serine proteinases', Protein Eng, 6(2), pp. 189-93.

Morris, G. M., Huey, R., Lindstrom, W., Sanner, M. F., Belew, R. K., Goodsell, D. S. and Olson, A. J. (2009) 'AutoDock4 and AutoDockTools4: Automated docking with selective receptor flexibility', J Comput Chem, 30(16), pp. 2785-91.

Mosimann, S. C., Cherney, M. M., Sia, S., Plotch, S. and James, M. N. (1997) 'Refined X-ray crystallographic structure of the poliovirus 3C gene product', J Mol Biol, 273(5), pp. 1032-47.

Nazzi, F. and Le Conte, Y. (2016) 'Ecology of Varroa destructor, the Major Ectoparasite of the Western Honey Bee, Apis mellifera', Annu Rev Entomol, 61, pp. 417-32.

Ohlenschläger, O., Wöhnert, J., Bucci, E., Seitz, S., Häfner, S., Ramachandran, R., Zell, R. and Görlach, M. (2004) 'The structure of the stemloop D subdomain of 
coxsackievirus B3 cloverleaf RNA and its interaction with the proteinase 3C', Structure, 12(2), pp. 237-48.

Patick, A. K., Binford, S. L., Brothers, M. A., Jackson, R. L., Ford, C. E., Diem, M. D., Maldonado, F., Dragovich, P. S., Zhou, R., Prins, T. J., Fuhrman, S. A., Meador, J. W., Zalman, L. S., Matthews, D. A. and Worland, S. T. (1999) 'In vitro antiviral activity of AG7088, a potent inhibitor of human rhinovirus 3C protease', Antimicrob Agents Chemother, 43(10), pp. 2444-50.

Pettersen, E. F., Goddard, T. D., Huang, C. C., Meng, E. C., Couch, G. S., Croll, T. I., Morris, J. H. and Ferrin, T. E. (2021) 'UCSF ChimeraX: Structure visualization for researchers, educators, and developers', Protein Sci, 30(1), pp. 70-82.

Rosenkranz, P., Aumeier, P. and Ziegelmann, B. (2010) 'Biology and control of Varroa destructor', J Invertebr Pathol, 103 Suppl 1, pp. S96-119.

Shang, L., Zhang, S., Yang, X., Sun, J., Li, L., Cui, Z., He, Q., Guo, Y., Sun, Y. and Yin, Z. (2015) 'Biochemical characterization of recombinant Enterovirus $713 \mathrm{C}$ protease with fluorogenic model peptide substrates and development of a biochemical assay', Antimicrob Agents Chemother, 59(4), pp. 1827-36.

Shen, M., Yang, X., Cox-Foster, D. and Cui, L. (2005) 'The role of varroa mites in infections of Kashmir bee virus (KBV) and deformed wing virus (DWV) in honey bees', Virology, 342(1), pp. 141-9.

Sun, D., Chen, S., Cheng, A. and Wang, M. (2016) 'Roles of the Picornaviral 3C Proteinase in the Viral Life Cycle and Host Cells', Viruses, 8(3), pp. 82.

Sweeney, T. R., Roqué-Rosell, N., Birtley, J. R., Leatherbarrow, R. J. and Curry, S. (2007) 'Structural and mutagenic analysis of foot-and-mouth disease virus 3C protease reveals the role of the beta-ribbon in proteolysis', $J$ Virol, 81(1), pp. 115-24.

Tan, Y. W., Ang, M. J., Lau, Q. Y., Poulsen, A., Ng, F. M., Then, S. W., Peng, J., Hill, J., Hong, W. J., Chia, C. S. and Chu, J. J. (2016) 'Antiviral activities of peptide-based covalent inhibitors of the Enterovirus 71 3C protease', Sci Rep, 6, pp. 33663.

Tentcheva, D., Gauthier, L., Zappulla, N., Dainat, B., Cousserans, F., Colin, M. E. and Bergoin, M. (2004) 'Prevalence and seasonal variations of six bee viruses in Apis mellifera L. and Varroa destructor mite populations in France', Appl Environ Microbiol, 70(12), pp. 7185-91.

Trott, O. and Olson, A. J. (2010) 'AutoDock Vina: improving the speed and accuracy of docking with a new scoring function, efficient optimization, and multithreading', $J$ Comput Chem, 31(2), pp. 455-61. 
Wang, J., Fan, T., Yao, X., Wu, Z., Guo, L., Lei, X., Wang, M., Jin, Q. and Cui, S. (2011) 'Crystal structures of enterovirus 71 3C protease complexed with rupintrivir reveal the roles of catalytically important residues', J Virol, 85(19), pp. 10021-30.

Weidner, J. R. and Dunn, B. M. (1991) 'Development of synthetic peptide substrates for the poliovirus 3C proteinase', Arch Biochem Biophys, 286(2), pp. 402-8.

Wilfert, L., Long, G., Leggett, H. C., Schmid-Hempel, P., Butlin, R., Martin, S. J. and Boots, M. (2016) 'Deformed wing virus is a recent global epidemic in honeybees driven by Varroa mites', Science, 351(6273), pp. 594-7.

Wilkesman, J. (2017) 'Cysteine Protease Zymography: Brief Review', Methods Mol Biol, 1626, pp. 25-31.

Winston, D. S. and Boehr, D. D. (2021) 'The Picornavirus Precursor 3CD Has Different Conformational Dynamics Compared to 3C', Viruses, 13(3).

Wu, Y., Dong, X. and Kadowaki, T. (2017) 'Characterization of the Copy Number and Variants of Deformed Wing Virus (DWV) in the Pairs of Honey Bee Pupa and Infesting', Front Microbiol, 8, pp. 1558.

Wu, Y., Liu, Q., Weiss, B., Kaltenpoth, M. and Kadowaki, T. (2020) 'Honey Bee Suppresses the Parasitic Mite Vitellogenin by Antimicrobial Peptide', Front Microbiol, 11, pp. 1037.

Wu, Y., Yuan, X., Li, J. and Kadowaki, T. (2021) 'DWV Infection', Front Microbiol, 12, pp. 631889.

Yao, C., Xi, C., Hu, K., Gao, W., Cai, X., Qin, J., Lv, S., Du, C. and Wei, Y. (2018) 'Inhibition of enterovirus 71 replication and viral 3C protease by quercetin', Virol $\mathrm{J}$, 15(1), pp. 116.

Yi, J., Peng, J., Yang, W., Zhu, G., Ren, J., Li, D. and Zheng, H. (2021) 'Picornavirus 3C - a protease ensuring virus replication and subverting host responses', J Cell Sci, 134(5).

Yue, C., Schröder, M., Gisder, S. and Genersch, E. (2007) 'Vertical-transmission routes for deformed wing virus of honeybees (Apis mellifera)', J Gen Virol, 88(Pt 8), pp. 2329-36. 
Table 1 IC50 values of DWV 3C ${ }^{\text {pro }}$ inhibitors

\begin{tabular}{|ll|}
\hline Compound & $\mathrm{IC}_{50}(\mu \mathrm{M})$ \\
\hline Rupintrivir & $0.36 \pm 0.03$ \\
\hline Ebselen & $1.66 \pm 0.02$ \\
\hline Disulfiram & $35.6 \pm 0.8$ \\
\hline GC376 & $55.2 \pm 4.0$ \\
\hline Carmofur & $126.7 \pm 6.2$ \\
\hline 6,7-dichloroquinoline-5,8-dione & $129.3 \pm 1.8$ \\
\hline Quercetin & $430 \pm 62.8$ \\
\hline Zinc & $15240 \pm 422$ \\
\hline
\end{tabular}




\section{Figure legends}

Figure 1. Enzymatic properties of the deformed wing virus (DWV) 3C protease $\left(3 C^{\text {pro }}\right)$.

(A) Optimum $\mathrm{pH}$ for protease activity. Multiple comparisons were made by the Tukey-Kramer method and the $P$-value between $\mathrm{pH} 6$ and other tested $\mathrm{pH}$ was $<0.001$. (B) Optimum temperature for protease activity. Multiple comparisons were made by the Tukey-Kramer method. Pairs with statistically significant differences are indicated by the $P$-values. (C) Dithiothreitol (DTT) requirement for protease activity. Multiple comparisons were made by the Dunnett method (one-tailed). Mean values \pm standard deviation (SD) (error bars) are shown $(\mathrm{n}=5)$ for A-C. (D) Protease activity with the indicated concentrations of glutathione-S-transferase (GST)-DWV 3C pro protein. (E) Protease activity $(\mathrm{V}, \mu \mathrm{M} / \mathrm{min})$ at the indicated peptide substrate concentrations (2-20 $\mu \mathrm{M})$. Mean values $\pm \mathrm{SD}$ (error bars) are shown $(\mathrm{n}=3)$ for $\mathrm{D}$ and $\mathrm{E}$.

Figure 2. Compounds that inhibit the activity of the deformed wing virus (DWV) $3 \mathrm{C}$ protease (3C $\left.{ }^{\text {pro }}\right)$.

Protease activity of DWV $3 \mathrm{C}^{\text {pro }}$ in the presence of increasing concentrations of rupintrivir, ebselen, disulfiram, GC376, carmofur, 6,7-dichloroquinoline-5,8-dione, quercetin, and zinc. Ebselen, disulfiram, carmofur were tested in the absence (blue line) or presence (red line) of $2 \mathrm{mM}$ dithiothreitol (DTT). Other compounds were tested in the presence of DTT. All data $(n=3)$ are shown at the indicated concentrations.

Figure 3. Ebselen suppresses RNA-dependent RNA polymerase (RdRP) synthesis in the deformed wing virus (DWV)-infected pupal head cells.

(A) Effect of increasing concentrations of ebselen on RdRP synthesis in DWV-infected (+) pupal head cells. Dimethyl sulfoxide (DMSO) was used as the control. RdRP precursor with $3 \mathrm{C}$ protease $(97 \mathrm{kDa})$ is indicated by a black arrow head. This band was absent in DWV-uninfected (-) cells. The replicate gel was stained with Instant Blue to show that equal amount of protein was applied in each lane. Molecular weight $(\mathrm{kDa})$ of the protein marker is indicated at the left. (B) Band intensity of the RdRP precursor was compared between DMSO and ebselen at the indicated concentrations by the Dunnett method (one-tailed). Mean values \pm SD (error bars) are shown $(\mathrm{n}=5)$. (C) Luminescence generated by the luciferase activity dependent on the intracellular ATP level was compared between the pupal head cells treated with DMSO or ebselen at the indicated concentrations by the Dunnett method (one-tailed). There was no significant 
difference between DMSO and $30 \mu \mathrm{M}$ ebselen. Mean values \pm SD (error bars) are shown $(n=5)$.

Figure 4. Structure-function analysis of the deformed wing virus (DWV) $3 C$ protease (3C $\left.{ }^{\text {pro }}\right)$.

(A) Structure of DWV 3C ${ }^{\text {pro }}$ predicted by AlphaFold2. The helix, strand, and coil structures are indicated by orchid, pale green, and wheat colors, respectively. $\beta$-ribbon is colored by cyan. The catalytic Cys-His-Asn triad is indicated by a square with a white dotted line. (B) Close-up view of the catalytic C2307-H2170-N2227 triad with distance information. (C) Positions of amino acid residues critical for the protease activity. (D) The position of $\mathrm{N} 2134$ that was well conserved between $3 \mathrm{C}^{\mathrm{pro}} \mathrm{s}$ of Iflaviruses is shown by rotating the image (C) by $180^{\circ}$. (E) The positions of H2190, D2304, and E2329, which are not essential for the protease activity, are shown together with the catalytic C2307-H2170-N2227 triad. (F) Protease activities of wild type (WT) 3C ${ }^{\text {pro }}$ and alanine substituted mutants. Compared to WT, all mutants showed decreased activities, except H2190A, D2304A, and E2329A (ns), as indicated by the Dunnett test (one-tailed, $\mathrm{n}=$ $5)$.

Figure 5. Amino acids interacting with rupintrivir in deformed wing virus (DWV) $3 \mathrm{C}$ protease $\left(3 \mathrm{C}^{\text {pro }}\right)$.

(A) Overall structure of rupintrivir-bound DWV 3C ${ }^{\text {pro }}$. Rupintrivir binding site is indicated by a square with white dotted line. (B) Surface view of rupintrivir bound DWV $3 \mathrm{C}^{\text {pro }}$. The binding site of rupintrivir was predicted by the molecular docking tool, AutoDock Vina. (C) Amino acids interacting with rupintrivir as well as the neighboring ones are indicated by different colors. Rupintrivir is also shown. (D) Amino acids in the deep right groove of the substrate-binding domain created by $\beta$-ribbon are indicated by rotating the image (C) $45^{\circ}$ without rupintrivir. (E) Sixteen amino acids interacting with rupintrivir. Hydrogen bonds are indicated by red dotted lines.

Figure 6. Self-cleavage of the deformed wing virus (DWV) $3 \mathrm{C}$ protease $\left(3 \mathrm{C}^{\text {pro }}\right)$ and its synthesis in the virus-infected honey bee cells.

(A) Sodium dodecyl sulfate-polyacrylamide gel electrophoresis (SDS-PAGE) of purified wild type (WT) and three mutant (C2307A, Q2118A, and E2180A) glutathione-S-transferase (GST)-DWV $3 \mathrm{C}^{\text {pro }}$ proteins. The $30 \mathrm{kDa}$ band co-purified with $56 \mathrm{kDa}$ GST-DWV $3 \mathrm{C}^{\text {pro }}$ is indicated by a black arrow head. Molecular weights $(\mathrm{kDa})$ of the protein marker are at the left. (B) SDS-PAGE of purified GST-DWV 3C 
incubated at $33{ }^{\circ} \mathrm{C}$ for the indicated time. (C) Western blotting of lysates of the control (-) or DWV-infected (+) honey bee pupal head cells by anti-3C ${ }^{\text {pro }}\left(3 C^{\text {pro }}\right)$ or anti-RdRP (RdRP) antibody. The replicate gel was stained with Instant Blue to show that equal amount of protein was applied in each lane. Mature $42 \mathrm{kDa} 3 \mathrm{C}^{\mathrm{pro}}$ and $55 \mathrm{kDa} \mathrm{RdRP}$ are indicated by black and white arrow heads, respectively. The $97 \mathrm{kDa}$ precursor of 3C and RdRP was detected by both anti-3C pro and anti-RdRP antibodies. The above mentioned three bands were specifically present in DWV-infected cells. Asterisk represents the non-specific band detected by the anti-3C $\mathrm{C}^{\text {pro }}$ antibody.

Supplementary figure 1. Confidence level of deformed wing virus (DWV) 3C proteases $\left(3 C^{\text {pro }}\right)$ structure predicted by AlphaFold2.

(A) Predicted IDDT per position shows the model confidence (out of 100) at each position of the amino acid sequence. (B) IDDT was superimposed on the predicted structure of DWV $3 C^{\text {pro }}$. Blue-colored region represents the predicted structure with high confidence.

\section{Supplementary figure 2. Alignment of the amino acid sequences of Iflavirus 3C proteases $\left(3 \mathrm{C}^{\text {pro }}\right)$.}

Amino acid sequences of 24 Iflavirus $3 \mathrm{C}^{\text {pro }}$, including DWV $3 \mathrm{C}^{\text {pro }}$, were aligned using MUltiple Sequence Comparison by Log-Expectation (MUSCLE). The conserved amino acids are indicated by asterisks, and similar amino acids are shown by either a period (.) or colon (:). The catalytic triad (C2307, H2170, and N2227) is highlighted in green, and the conserved amino acids substituted with alanine are shown in yellow. N2227 is not well conserved between Iflaviruses as highlighted in light blue. The self-cleavage site of DWV 3C ${ }^{\text {pro }}$, Q2118, is indicated in purple. The accession numbers and aligned sequences of each virus are shown after the aligned sequences.

\section{Supplementary figure 3 . The $3 \mathrm{C}$ protease $\left(3 \mathrm{C}^{\mathrm{pro}}\right)$ structures of four Iflaviruses and Dicistrovirus predicted by AlphaFold2.}

The $3 \mathrm{C}^{\text {pro }}$ structures of Brevicoryne brassicae virus (A), Laodelphax striatellus picorna-like virus 2 (B), Spodoptera exigua iflavirus (C), Sacbrood virus (D), and Cricket paralysis virus (E). The helix, strand, and coil structures are indicated by orchid, pale green, and wheat colors, respectively. $\beta$-ribbons are colored by cyan. The catalytic triad with amino acid residues is indicated by a square with a white dotted line. 


\section{Supplementary figure 4. Surface views of the $3 \mathrm{C}$ proteases $\left(3^{\text {pro }}\right)$ of four Iflaviruses and Dicistrovirus.}

Surface views of the $3 \mathrm{C}^{\mathrm{pro}} \mathrm{s}$ of Brevicoryne brassicae virus (A and B), Laodelphax striatellus picorna-like virus 2 (C), Spodoptera exigua iflavirus (D), sacbrood virus (E), and cricket paralysis virus ( $\mathrm{F}$ and $\mathrm{G}$ ). Images $\mathrm{B}$ and $\mathrm{G}$ were obtained by rotating images $\mathrm{A}$ and $\mathrm{F}$ at $60^{\circ}$ and $90^{\circ}$, respectively. Cys, His, and Asn/Ser/Glu/Asp residues in the predicted catalytic triad are indicated by khaki, pale green, and magenta colors, respectively. $\beta$-ribbons are highlighted in silver. 
A

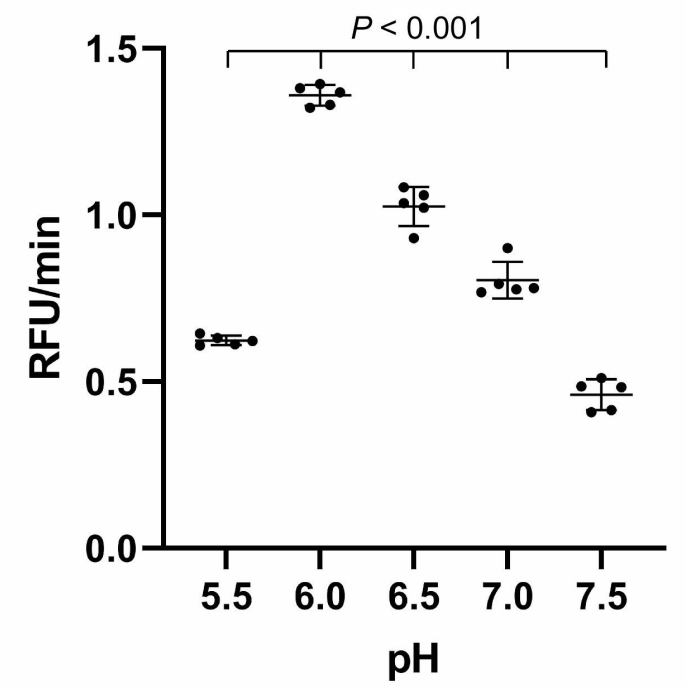

D

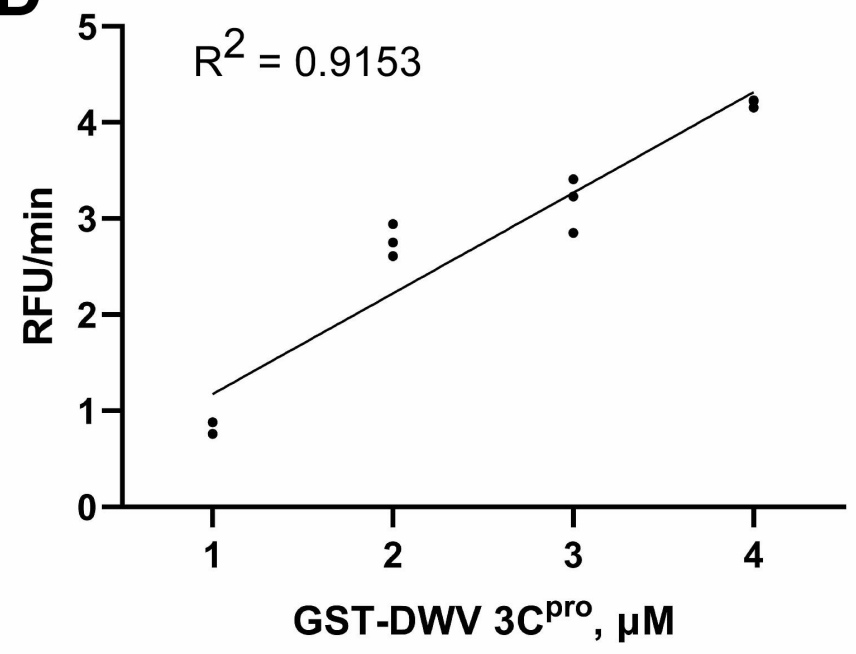

B

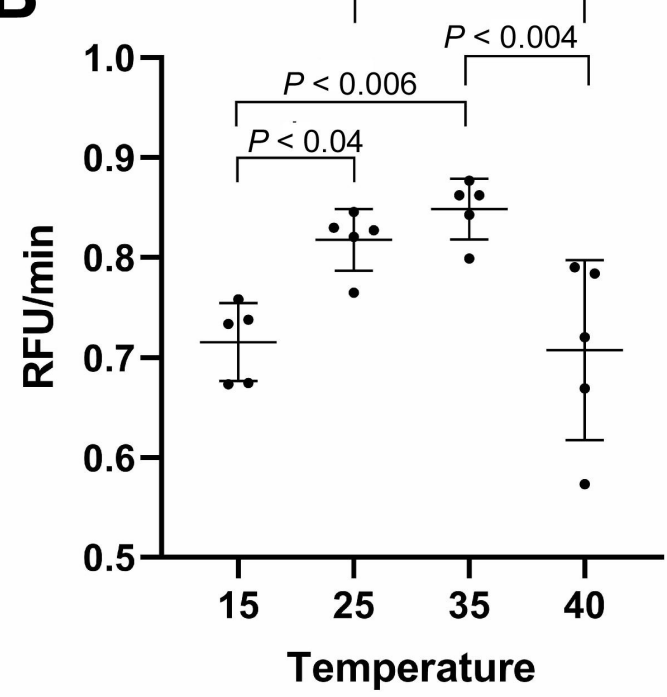

C

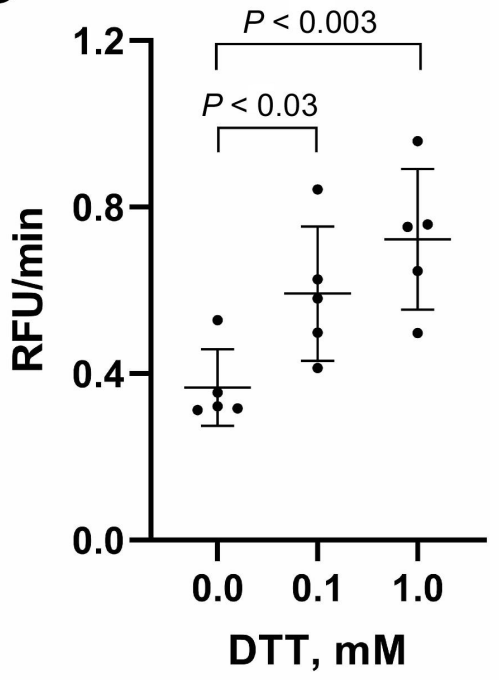

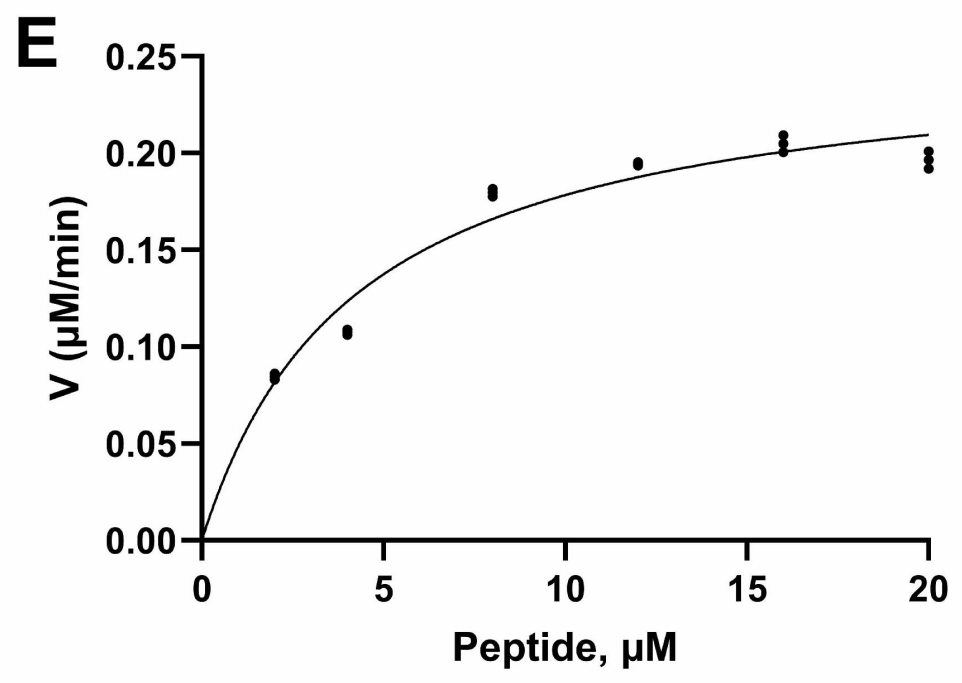




\section{Rupintrivir}

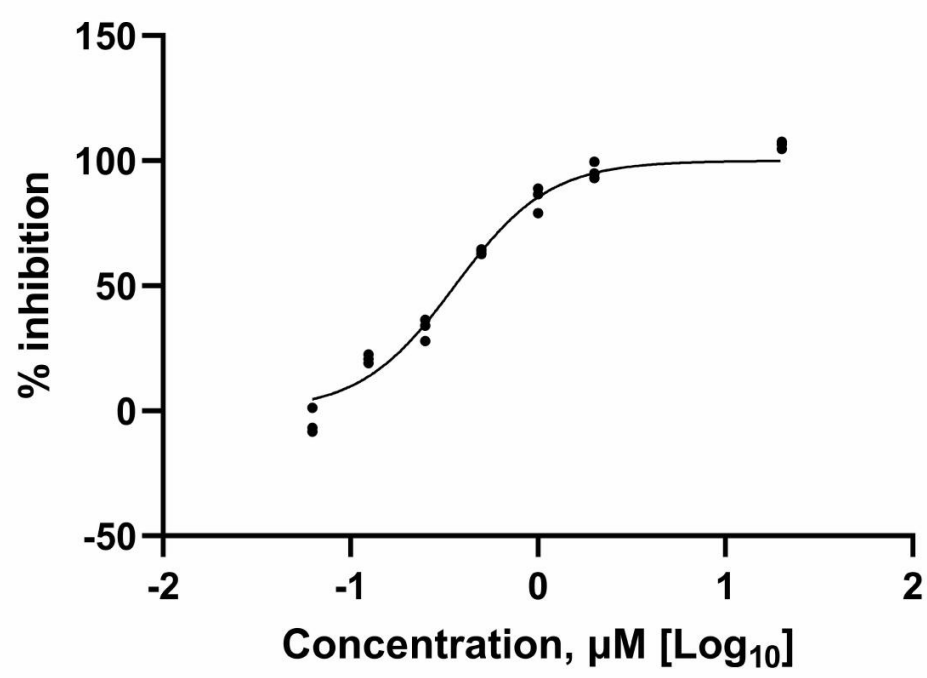

GC376

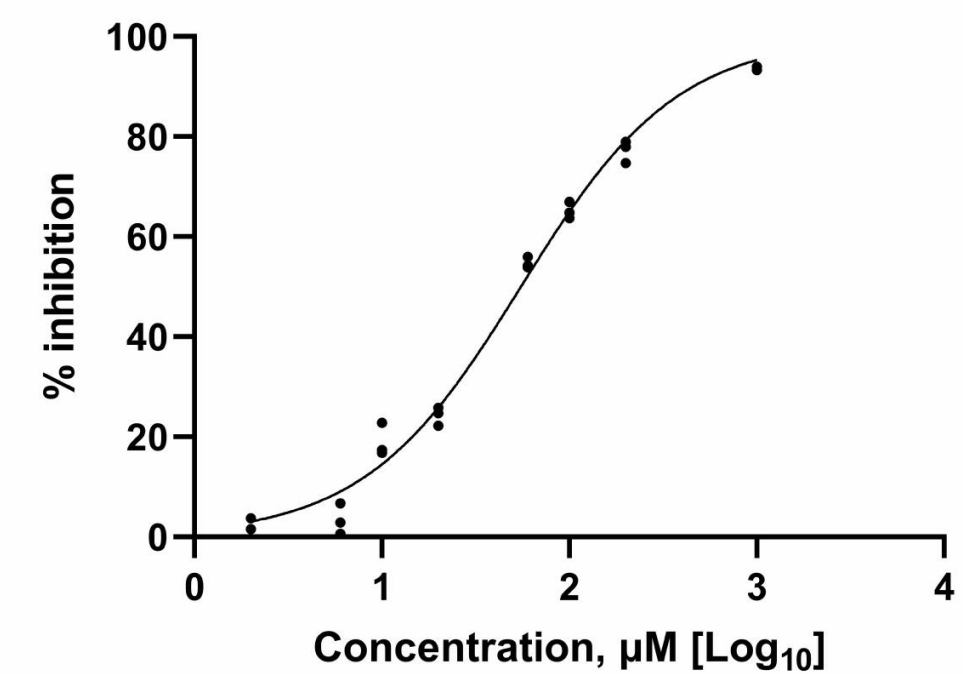

Quercetin

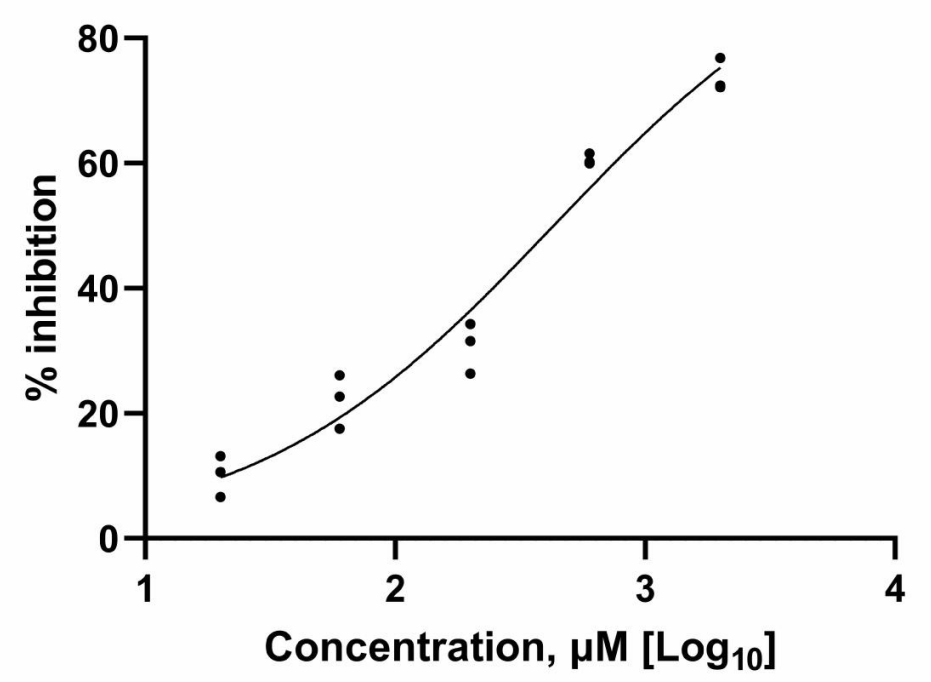

Ebselen

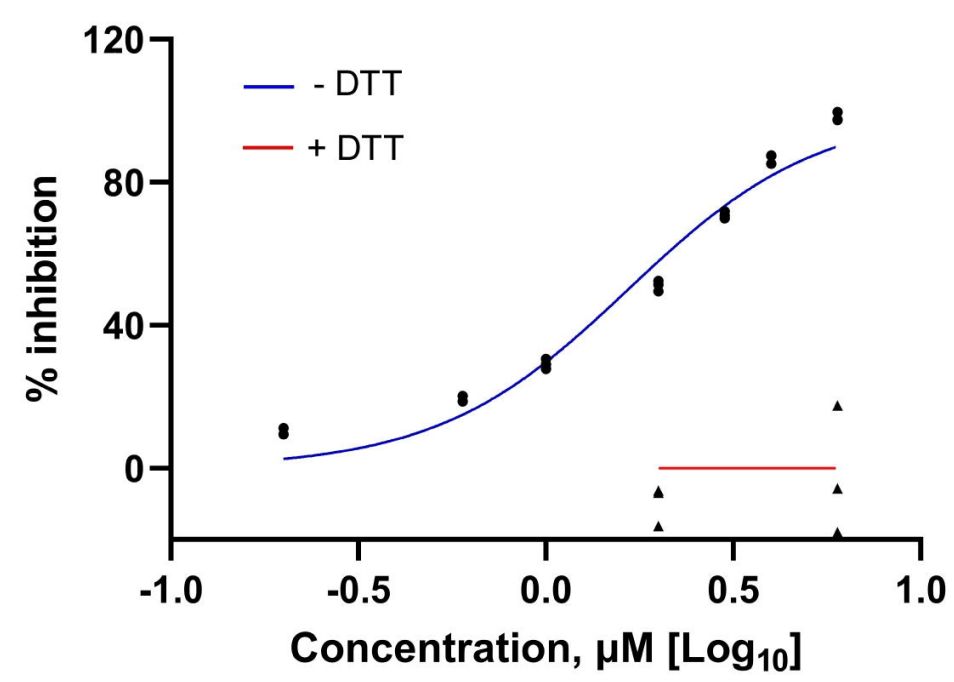

Carmofur

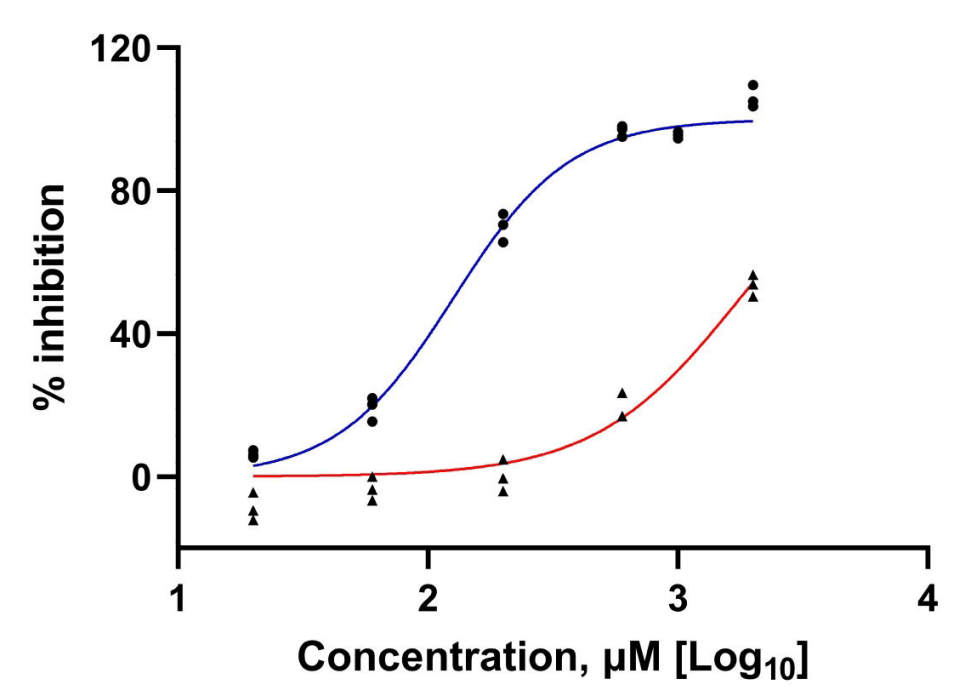

Zinc

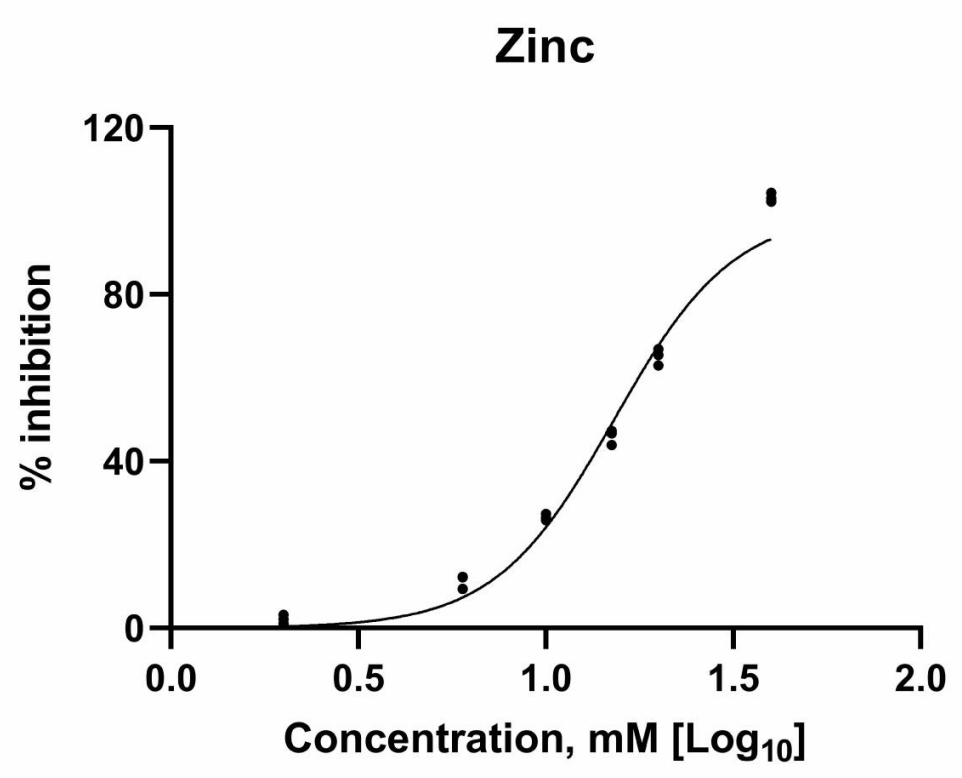

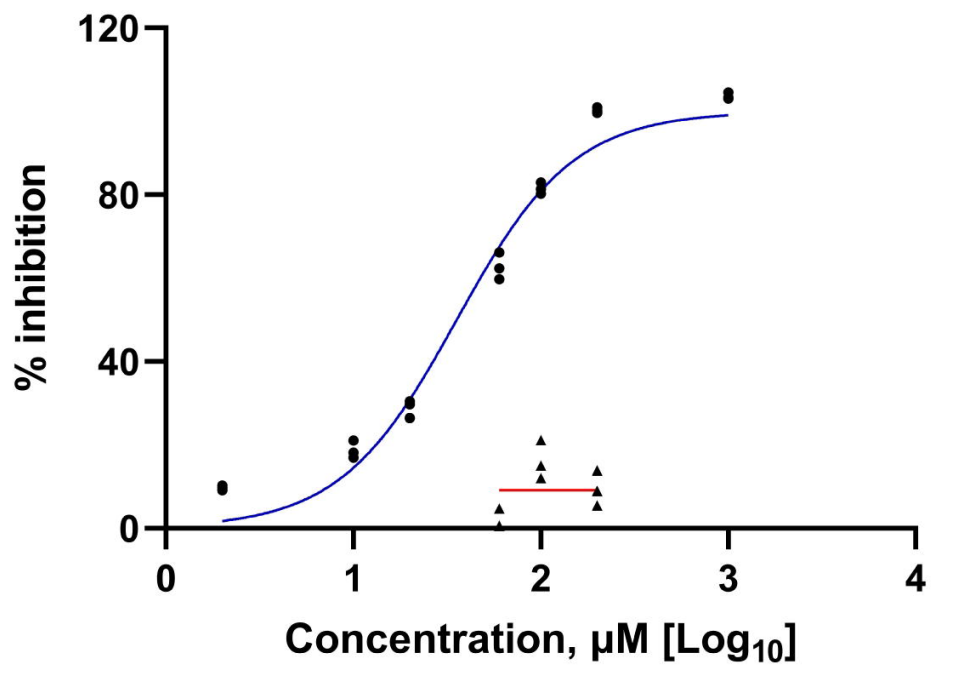

6,7-dichloroquinoline-5,8-dione

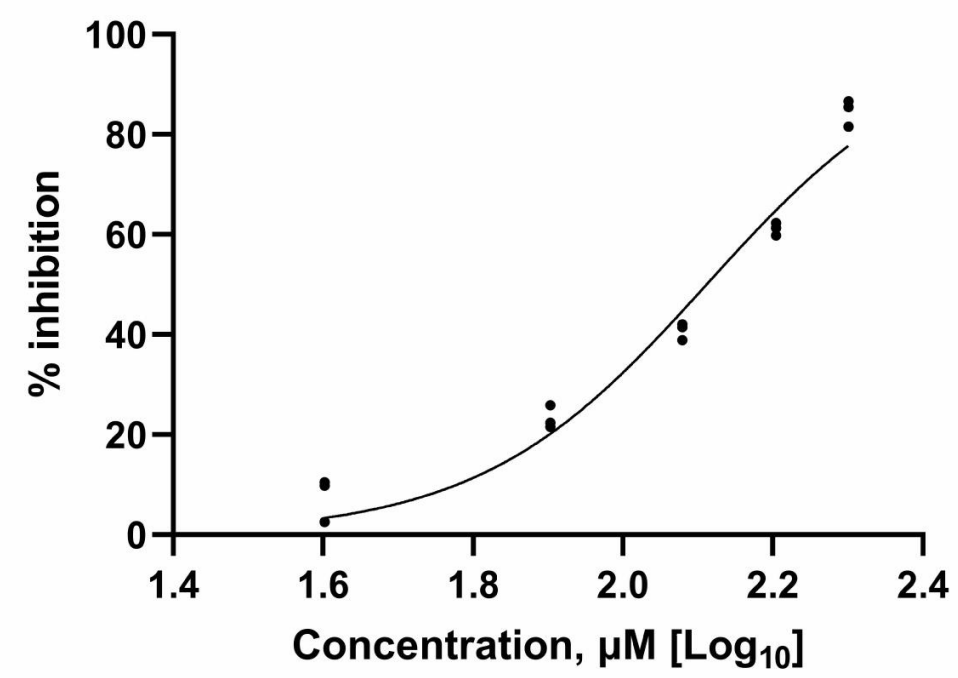


$\mathrm{A}++++-$ DWV kDa $\quad 0 \quad 30100250 \quad 0$ Ebselen, $\mu \mathrm{M}$ $130-$ 100 70 $55-$ $40-$ $35-$ 25kDa $100-$ $70-$ 55-
B

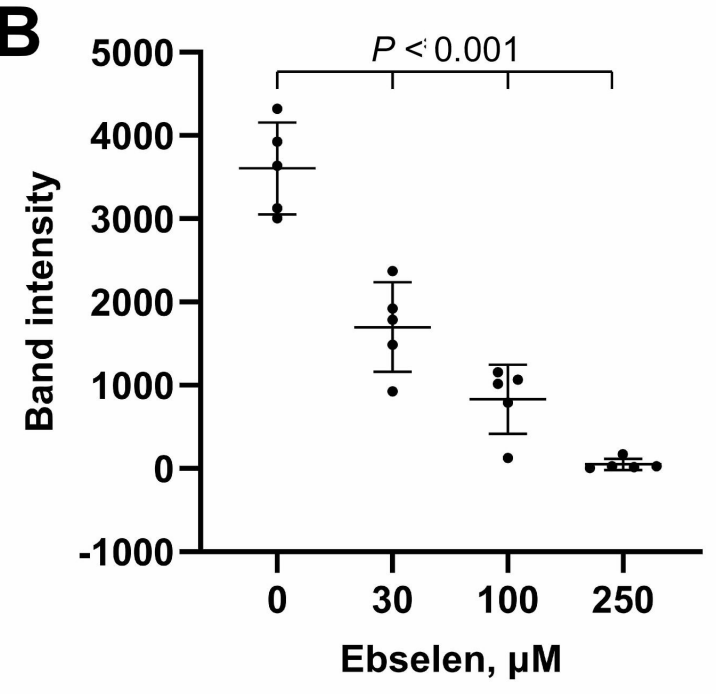

C

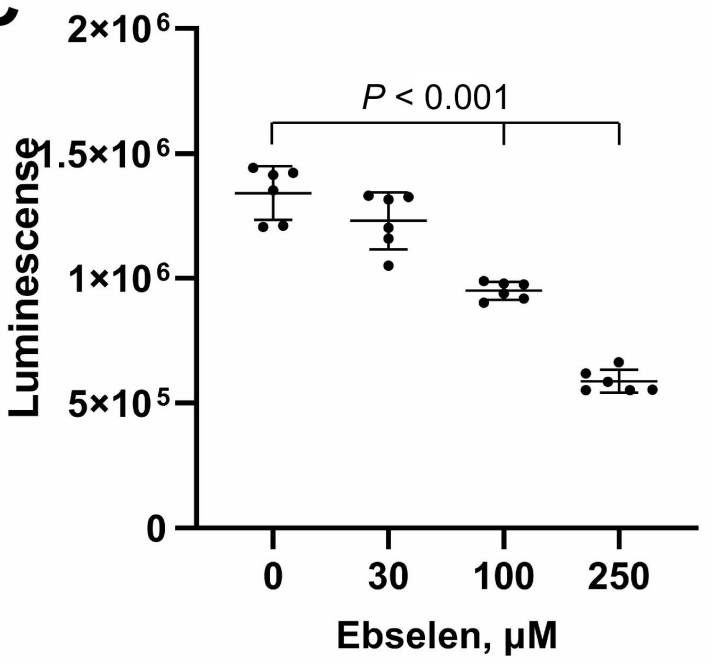



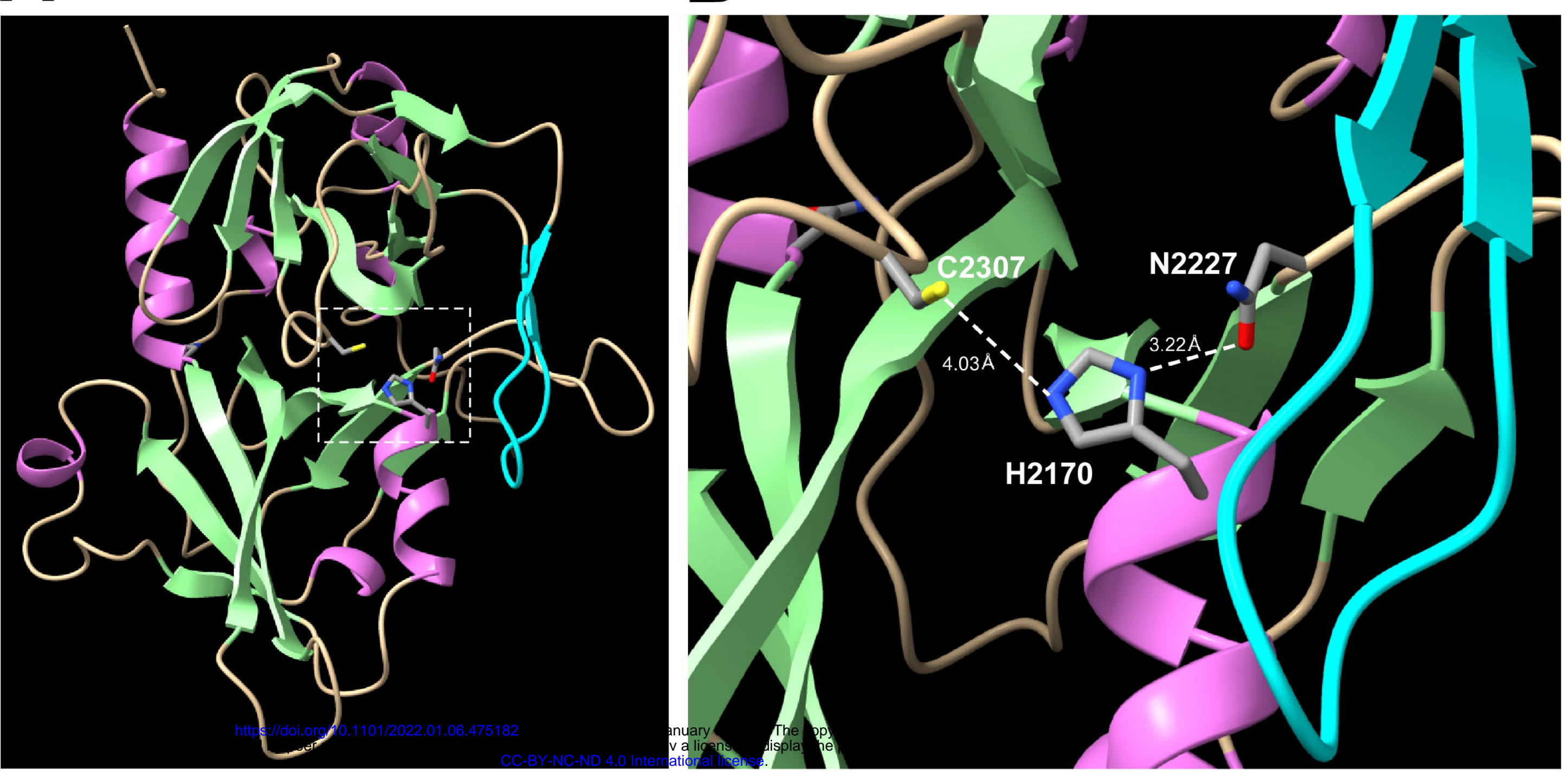

C

D
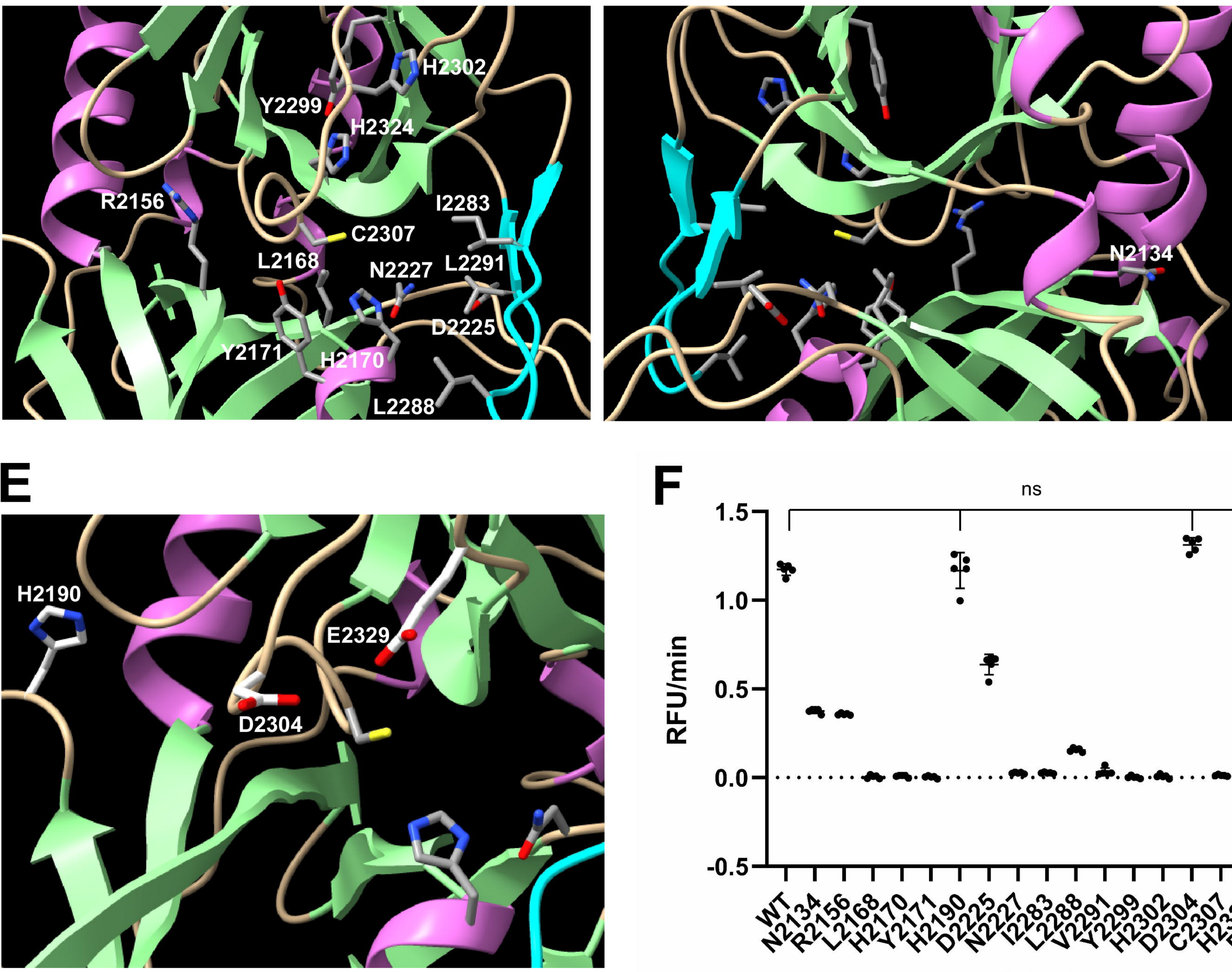

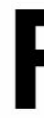

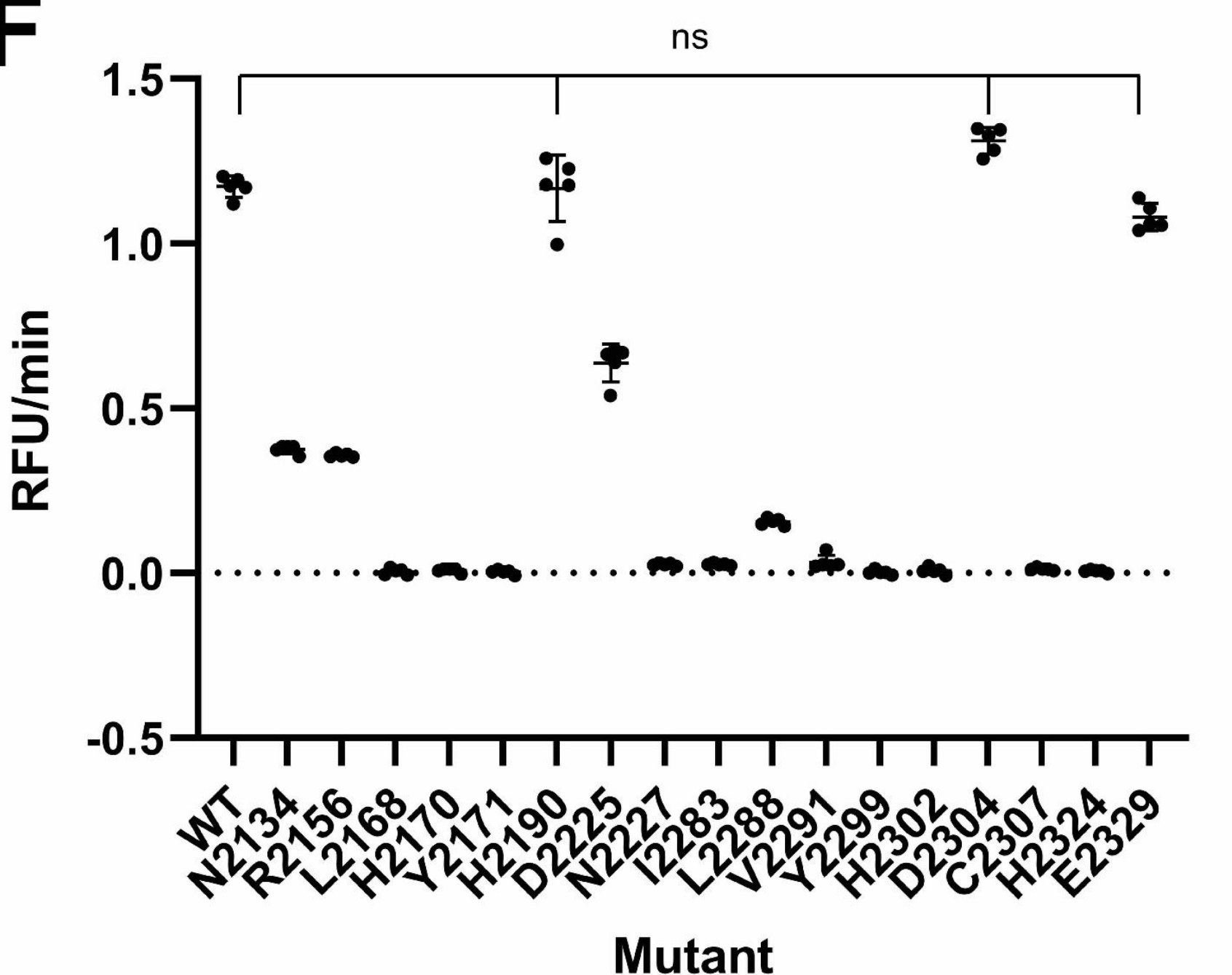

\section{Mutant}


$\mathrm{kDa}$

$130-$

$100-$

$70-$

$55-$

$40-$

$35-$

25-

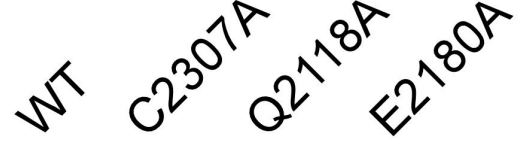

$\mathrm{kDa}$

$\begin{array}{lllllll}0 & 3 & 6 & 9 & 12 & 18 & \mathrm{~h}\end{array}$
130-

$100-$

$70-$

$55-$

40-

$35-$

25-

C

$\mathrm{kDa}$

Instant Blue

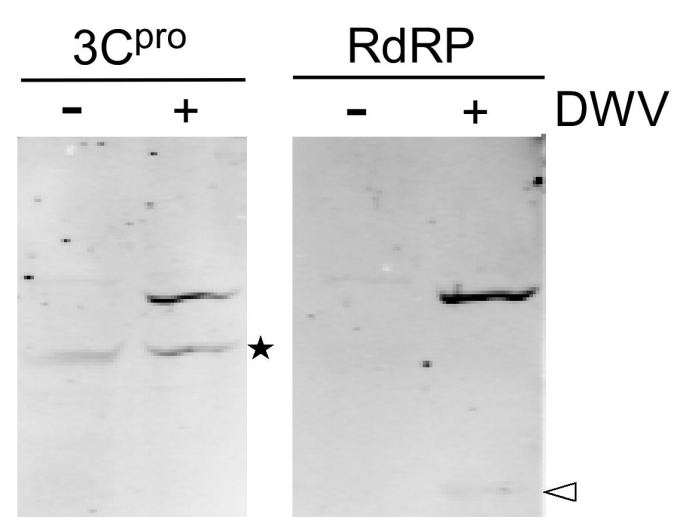

$40-$

$35-$

25- 